\title{
La teoría de interacción espacial como síntesis de las teorías de localización de actividades comerciales y de servicios
}

\author{
Carlos Garrocho Rangel*
}

\begin{abstract}
The Spatial Interaction Theory (SIT) is one of the most simple and elegant theories of commercial geography. Its simplicity lies mainly in its power to analyse and explain both the consumer spatial behaviour and the localisation patterns of commercial and service units. Moreover, it is possible to formulate the SIT in a number of simulation models that can be used to assist entrepreneurs in the locational decision making. This article shows that the SIT embraces the arguments of the main theories of commercial and service unit localisation and therefore it turns out to be the main theoretical and operational platform of commercial geography, in terms of spacial planning.
\end{abstract}

Keywords: Commercial geography, spacial interaction theory, spacial planning

\section{Resumen}

La teoría de interacción espacial (TIE) es una de las teorías más sencillas y elegantes con que cuenta la geografía comercial. En su sencillez radica gran parte de su potencial para analizar y explicar tanto la conducta espacial de los consumidores, como los patrones de localización de unidades comerciales y de servicios. Adicionalmente, la TIE se puede traducir en una gran variedad de modelos de simulación para apoyar a los empresarios en la toma de decisiones locacionales. En este artículo se demuestra que la TIE incluye los argumentos de las principales teorías de localización de unidades comerciales y de servicios, por lo que, en términos de planeación espacial, resulta la principal plataforma teórica y operativa de la geografía comercial.

Palabras clave: geografía comercial, teoría de interacción espacial, planeación espacial. 


\section{Introducción}

Una de las decisiones más difíciles que enfrentan los inversionistas comerciales es dónde localizar sus negocios. La respuesta puede definir el destino de su inversión, de su trabajo, de los empleos que generan y de sus sueños empresariales, ya que de ella depende, en gran medida, la capacidad de sus unidades de negocio para competir exitosamente por el mercado. No es gratuito entonces que se diga, incluso, que "hay tres aspectos cruciales que se deben cuidar en una unidad comercial: localización, localización y localización" (Jones y Simmons, 1990).

La mayoría de las veces, las decisiones locacionales de las firmas comerciales se basan en el conocimiento práctico y en la intuición del empresario. Sin embargo, conforme aumenta la inversión y la escala de los negocios, se incrementan también los riesgos y costos de tomar decisiones locacionales equivocadas. La pura intuición -como un juego de dados que decide la estrategia locacional de la empresa- deja de ser satisfactoria para los inversionistas, y es entonces cuando se requieren métodos más sistemáticos, fundados más en la inteligencia que en el azar, que permitan identificar la localización más ventajosa para un negocio determinado, en mercados altamente competitivos.

A pesar de la importancia social y económica que implica la toma de decisiones locacionales de firmas comerciales y de servicios, el sector académico se ha ocupado poco de este tema, ${ }^{1} \mathrm{y}$ cuando lo ha hecho, los análisis son predominantemente agregados (por ejemplo, Alonso, 1964; Alexander, 1979). Es decir, considerando al comercio y a los servicios como sectores de actividad -o como usos del suelo- y no como firmas individuales. Esto explica que la mayoría de las investigaciones académicas publicadas sobre localización comercial y de servicios sean de escala nacional, regional o urbana, y sólo una parte minoritaria de escala intraurbana (Berry, et al., 1988). Revisando la literatura especializada, se observa que la principal intención de los trabajos agregados es describir patrones y procesos urbano-sectoriales, con la idea de confirmar o generar teorías de planeación del desarrollo urbano o regional, pero no de producir conocimiento aplicable a la planeación espacial y comercial de firmas concretas, de carne y hueso. Firmas inmersas en un despiadado juego de inteligencia en el que sólo sobreviven las más aptas.

${ }^{1}$ Sobre todo, si comparamos la atención que ha dirigido a otras áreas del análisis locacional, particularmente a las relacionadas con la industria y con los servicios públicos. 
No obstante, existe un pequeño nicho académico -aún poco conocido en México- en el que el principal interés ha sido la planeación locacional de unidades comerciales específicas, entendida como una parte integral de la estrategia de competencia de la firma. Este nicho de investigación es la geografía comercial, ${ }^{2}$ y ha ido ganando terreno, especialmente en algunas universidades británicas, canadienses y norteamericanas.

Convencionalmente, se ha considerado que existen dos tradiciones en la geografía comercial: una predominantemente teórica (por ejemplo, Christaller, 1966; Lösch, 1954; Berry, et al., 1988; Parr, 1981) y otra de naturaleza aplicada (que se inicia con los trabajos de Reilly, 1931 y Applebaum, 1966; y continúa con los de Wilson 1980 y 1986; y Fotheringham, 1983a; 1985 y 1986a y b). Sin embargo, en las últimas dos décadas han aparecido diversos textos que intentan darle mayor sentido práctico a la teoría y mejor contenido teórico a la investigación práctica (Davies y Rogers, 1984; Ghosh y McLafferty, 1987; Wrigley, 1988; Jones y Simmons, 1990; Jagoe, 2002). Esta tendencia contemporánea de la geografía comercial busca mezclar coherentemente el conocimiento teórico y la experiencia empírica, para resolver complejos problemas locacionales en el mundo real. Es decir, se apoya en la teoría disponible (y en la que va generando) para diseñar estrategias locacionales de firmas concretas - con nombre y apellidocon el propósito de incrementar sus probabilidades de éxito en los agresivos entornos comerciales en los que operan. Este gran propósito de la geografía comercial -incidir de verdad en la realidad a partir de la investigación académica- se ha traducido en una de las más ambiciosas agendas de investigación que existen entre las disciplinas que abarcan lo urbano-regional.

No obstante, uno de los problemas más aparentes de la geografía comercial es la diversidad de enfoques teóricos de los que se alimenta para explicar la distribución espacial de las unidades comerciales y de servicios, y apoyar así la toma de decisiones locacionales de las firmas. Es cierto que esta diversidad de enfoques enriquece el análisis, pero, al mismo tiempo, dificulta lograr la mezcla balanceada entre teoría y práctica que busca la moderna geografía comercial. Sin embargo -y este es el punto central del artículo- al analizar en detalle los enfoques conceptuales disponibles se detectan diversos argumentos en común y se descubre que todos los enfoques pueden ser sintetizados en una sola estructura

${ }^{2}$ En la literatura anglosajona se le conoce como commercial geography o marketing geography. 
conceptual: la que ofrece la teoría de interacción espacial (TIE). Demostrar esta aseveración es el principal objetivo de este texto, lo que resulta relevante porque así se contará con una visión más integral de la teoría disponible; una visión que al combinar coherentemente conceptos teóricos abstractos originados en diversas disciplinas, con poderosas herramientas de planeación, contribuya a diseñar mejores estrategias de localización para unidades comerciales y de servicios.

El texto se organiza de la siguiente forma: primero se presentan los principales enfoques que explican la localización espacial de las unidades comerciales, y luego se integran todos en la estructura conceptual de la teoría de interacción espacial. Se inicia con la explicación de la teoría de la conducta del consumidor (el enfoque microeconómico), pero traduciéndola a términos espaciales, lo que en sí mismo constituye, desde un punto de vista pedagógico, un valor agregado de este texto. Esta teoría es, sin duda, la más elegante y acabada de todas las que aquí se presentan, y por ello se explica con todo detalle. El segundo enfoque que se examina es la teoría de lugar central, que es fundamental para entender la distribución espacial de las actividades comerciales y constituye uno de los pilares, no sólo de la geografía comercial sino de la planeación regional. El tercer enfoque analizado es la teoría de la subasta del suelo urbano, que se presenta principalmente con el fin de redondear la revisión de la teoría disponible y mostrar que incluso este enfoque agregado está implícito en la teoría de interacción espacial. El cuarto y último enfoque que se revisa es, naturalmente, la teoría de interacción espacial, destacando sus principales argumentos y sus notables ventajas prácticas para apoyar la planeación locacional de unidades comerciales y de servicios.

Una vez perfiladas las piezas de la estructura conceptual, se procede a 'ensamblarlas', siguiendo la lógica de la TIE, para demostrar que ésta considera, implícita o explícitamente, los principales argumentos y conceptos de los demás enfoques teóricos sobre la distribución espacial de las unidades comerciales y de servicios, con una significativa ventaja que la hace superior a los demás en la arena de la planeación locacional: su posibilidad para traducir los conceptos teóricos en modelos espaciales de simulación de mercados.

Con el fin de ganar en claridad, se utiliza un lenguaje deliberadamente sencillo y se presentan diversas gráficas y ejemplos numéricos que apoyan las líneas de argumentación de este texto. 
Finalmente, se concluye con una bibliografía de las referencias citadas a lo largo del documento.

\section{Principales enfoques teóricos sobre el comportamiento espacial de las actividades comerciales}

El desarrollo de los mercados comerciales depende de qué oferentes y consumidores coincidan en el espacio. ${ }^{3}$ En la literatura especializada es posible identificar, al menos, cuatro enfoques conceptuales que intentan explicar el comportamiento espacial de oferentes y consumidores. Como se verá, estos enfoques son distintos, pero complementarios, y pueden ser satisfactoriamente acomodados en la estructura conceptual de la teoría de interacción espacial, para formar así una sólida plataforma analítica que apoye la toma de decisiones locacionales de unidades comerciales y de servicios en el mundo real.

\subsection{Teoría espacial de la conducta del consumidor: el enfoque microeconómico}

Uno de los supuestos básicos de la microeconomía es que los consumidores tratan de maximizar su utilidad (satisfacción), mientras que los empresarios tratan de maximizar sus beneficios. Los primeros gastan su limitado ingreso de forma que se eleve al máximo su bienestar; y los segundos tratan de organizar eficientemente sus actividades y anticipar las preferencias de los consumidores, con el fin de incrementar sus ganancias (Ferguson y Gould, 1983). Este marco de referencia mínimo permite analizar sistemáticamente la conducta económica de los consumidores y de los empresarios.

Sin embargo, la teoría microeconómica, expresada de manera ortodoxa, no considera la variable espacial, y por lo tanto no puede explicar el comportamiento de los agentes económicos en el territorio. Es necesario, entonces, traducirla a términos territoriales para derivar algunos argumentos teóricos que permitan en-

\footnotetext{
${ }^{3}$ Salvo excepciones, como en el comercio por catálogo, o el que se hace vía televisión o Internet. Y aún en ellos la variable espacial estaría presente, pues los costos de transporte (envío) del bien -del oferente al consumidor- le son cargados a este último, afectando su toma de decisiones (por ejemplo, los costos de envío internacionales son elevados en muchas compras por Internet); a menos de que se trate de un bien intangible constante, o que se manejen costos de envío fijos, donde unos consumidores subsidian a otros, como ocurre en el caso de ciertos productos como Coca-Cola, Pepsi-Cola, Bimbo, Sabritas y otros.
} 
tender la lógica de la conducta espacial de los consumidores y de las decisiones locacionales de los empresarios. Esto es lo que se intenta hacer en los siguientes párrafos.

\subsubsection{Utilidad, patrones de viaje y curvas de indiferencia}

De acuerdo con la teoría microeconómica, el consumidor asiste a unidades comerciales -es decir, consume servicios de comercialización- porque obtiene cierta utilidad, ya que en esas unidades satisface su necesidad de bienes o servicios. Como el consumidor busca maximizar su utilidad, que es el objetivo económico de todos los consumidores, acude a la unidad que se ajuste más a sus preferencias personales.

Usualmente existen varios puntos de oferta donde el consumidor puede realizar sus compras. Esto significa que el consumidor puede combinar sus visitas a los puntos de oferta con la idea de maximizar su utilidad. Es más, puede diseñar numerosas combinaciones de visitas (es decir, diferentes patrones de viajes a las unidades comerciales) que le reporten utilidades iguales. ${ }^{4} \mathrm{Si}$ se grafican en un espacio cartesiano diversos conjuntos de combinaciones de viajes de utilidad equivalente (Figura 1), se generan lo que los economistas llaman curvas de indiferencia. Evidentemente, el consumidor prefiere las combinaciones que implican mayor consumo total, porque le producen mayor utilidad. Es decir, prefiere siempre las combinaciones que se encuentren en las curvas de indiferencia más altas (las más alejadas del origen en un espacio cartesiano).

Por ejemplo, en la Figura 1 se representan varios conjuntos de combinaciones de visitas (patrones de viajes) a dos unidades comerciales $(X$ y $Y$ ). Los puntos $A$ y $B$ representan dos combinaciones diferentes de viajes a las unidades $X$ y $Y$, pero, en este ejemplo, ambas combinaciones le proporcionan la misma utilidad al consumidor, por lo que se localizan en la misma curva de indiferencia (la número I). En cambio, el punto $C$ se localiza en una curva de indiferencia más alta (la curva $I V$ ), lo que quiere decir que se trata de una combinación que permite mayor consumo (y genera mayor utilidad), que las combinaciones $A$ o $B$. Por lo tanto, el consumidor preferirá la combinación $C-y$ todas las que están en esa

\footnotetext{
${ }^{4}$ Como se observa, en esta sección significa lo mismo decir visitas a unidades comerciales que consumo de servicios de comercialización, o que viajes a establecimientos comerciales.
} 
misma curva de indiferencia- sobre las otras combinaciones, porque la utilidad que le reporta es mayor.

\section{Figura 1}

\section{Curvas de indiferencia}

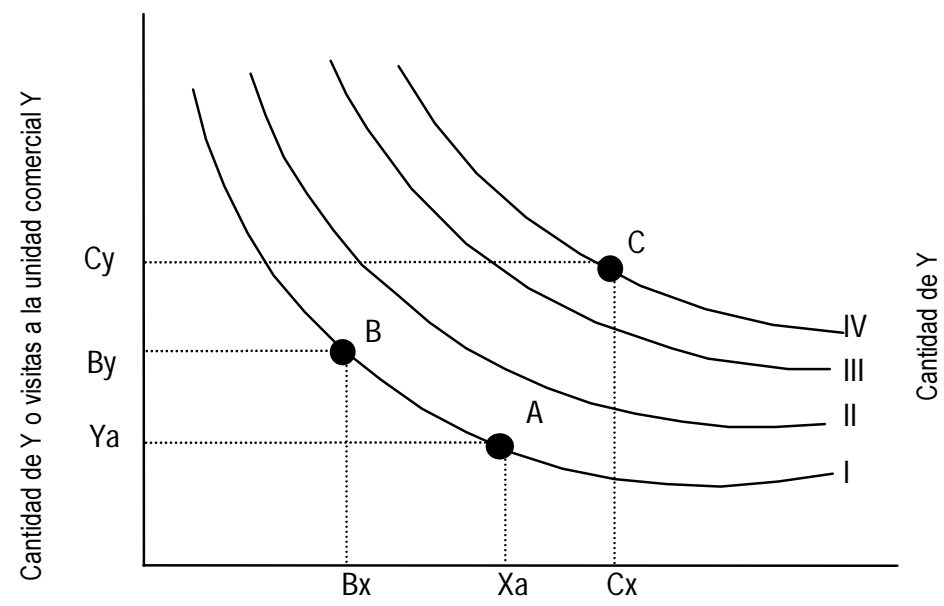

Cantidad de $X$ o visitas a la unidad comercial $X$

\subsubsection{Patrones de viajes considerando ingresos limitados}

Ahora bien, supongamos dos unidades comerciales $(X, Y)$ que pertenecen a un mismo grupo estratégico (es decir, a un grupo de firmas que tienen imagen similar, que ofrecen mercancías parecidas a precios similares y que se orientan al mismo mercado), y cuya principal diferencia es la distancia a la que se localizan del consumidor: $X$ se localiza a $x$ unidades del consumidor, y $Y$ a $y$ unidades. En este escenario, el consumidor decide sus viajes a las unidades comerciales en función de los precios de transporte. Por lo tanto, sean $p_{x}$ el costo de transporte unitario a la unidad comercial $X$, y $p_{y}$ el costo de transporte unitario a $Y .^{5}$ Supongamos, además, que el consumidor dispone de un monto limitado de recursos $M$-estimado en términos monetarios- para gastar en transportarse a las unidades comerciales. En consecuencia, la cantidad que se gaste en acudir a $X$ (que se puede expresar como $x p_{x}$ ) más la que gaste en acudir a $Y\left(y p_{y}\right)$ no puede exceder los recursos disponibles. Por tanto,

${ }^{5}$ Por costo de transporte unitario se entiende el costo de transporte por cada unidad de distancia. 


$$
M=x p_{x}+y p_{y}
$$

La expresión $M / y p_{y}$ indica los viajes que el consumidor puede realizar al centro comercial $Y$, si no acude ni una sola vez al centro comercial $X ; \mathrm{y} M / x p_{x}$ representa los viajes que el consumidor puede realizar a $X$ si no acude ni una vez a $Y$.

Estos valores pueden localizarse en un plano cartesiano: las coordenadas del primero serían $\left(0, M / y p_{y}\right)$ y las del segundo $(M /$ $\left.x p_{x}, 0\right) .{ }^{6} \mathrm{Si}$ se unen estos dos puntos se genera una recta que relaciona precios y recursos disponibles, y que recibe el nombre de linea de presupuesto (Figura 2). Cada punto de la línea de presupuesto representa una combinación posible -no necesariamente deseable como las que representan las curvas de indiferencia- de viajes a los centros comerciales $X$ y $Y$. Por lo tanto, la línea de presupuesto representa todas las posibilidades que tiene el consumidor -con sus recursos disponibles- de combinar su gasto en transportarse a ambas unidades comerciales.

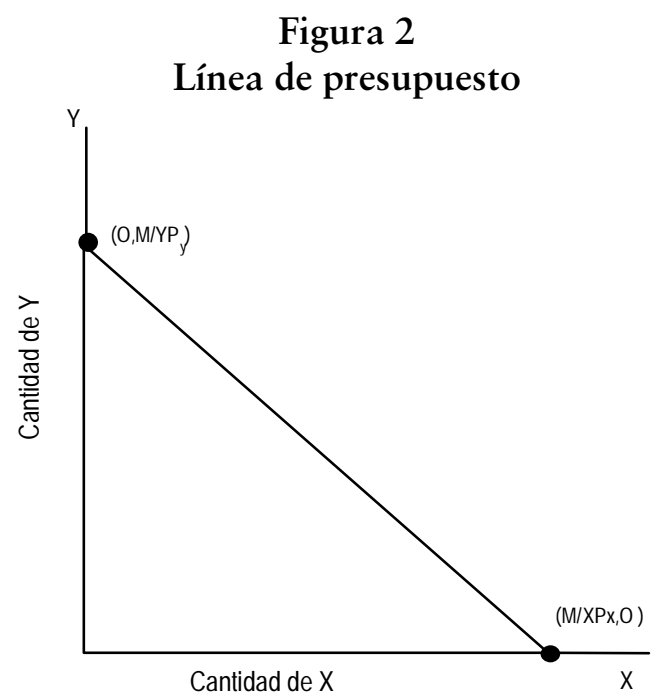

\footnotetext{
${ }^{6}$ Las coordenadas $\left(0, \mathrm{M} / \mathrm{yp}_{\mathrm{y}}\right)$ representan la situación en la que todos los recursos disponibles para gastar en transporte se destinan a viajar a la unidad comercial Y (por eso el valor de la ordenada es $\mathrm{M} / \mathrm{yp}_{\mathrm{y}}$ ) y por lo tanto no es posible acudir ni una sola vez a la unidad X (como el consumidor no acude a X, se puede decir que el consumo de X es igual a cero, que es, precisamente, el valor de la abcisa). Las coordenadas del otro punto $\left(\mathrm{M} / \mathrm{xp}_{\mathrm{x}}, 0\right)$ representan la situación opuesta: todos los recursos se destinan a viajar a la unidad comercial $\mathrm{X}$ (por eso el valor de la ordenada es $\mathrm{M} / \mathrm{xp}_{\mathrm{x}}$ ) y por lo tanto no se acude ni una sola vez a la unidad Y (como el consumo de $\mathrm{Y}$ es cero, el valor de la ordenada también es cero). El primer punto se localiza sobre el eje de las ordenadas (exactamente a $\mathrm{M} / \mathrm{yp}_{\mathrm{y}}$ unidades del origen), y el segundo sobre el de las abcisas (a $\mathrm{M} / \mathrm{xp}_{\mathrm{x}}$ unidades del origen).
} 
Todo esto se puede entender mejor con un ejemplo. Supongamos que un consumidor se encuentra a 20 kilómetros de la unidad comercial $X$ y a 10 kilómetros de la unidad comercial $Y$; que el costo unitario de transporte es 10 pesos por kilómetro; y que los recursos disponibles del consumidor para transporte son igual a 1,200 pesos. Esto significa que un viaje completo (ida y regreso) a $X$ implica 400 pesos. Por su parte, un viaje completo a $Y$ sólo requiere de la mitad de recursos que el viaje a $X$ (200 pesos). Como el consumidor dispone de 1,200 pesos, los extremos de su línea de presupuesto para gasto en transporte son, para el caso de $Y: 1,200 / 200=6$, y para el caso de $X: 1,200 / 400=3$. Esto significa que si el consumidor utiliza todos sus recursos disponibles en viajar a $X$, podrá visitar esa unidad comercial en tres ocasiones (pero no podrá visitar la unidad Y ni una sola vez); por el contrario, si concentra todo su gasto en viajar a $Y$, podrá visitar esa unidad seis veces (pero no podrá realizar ningún viaje a la unidad $X$ ).

Si se grafican estos valores en un plano cartesiano, las coordenadas de los puntos extremos de la línea de presupuesto son: para $X(3,0)$ y para $Y(0,6)$. Entre estos dos puntos extremos se ubican otras combinaciones posibles de viajes a las unidades comerciales. Por ejemplo, en la Figura 3, el punto $A$ representa una combinación de un viaje a $X$ (400 pesos) y cuatro viajes a $Y$ ( 800 pesos), y el punto $B$ dos viajes a $X$ ( 800 pesos) y dos viajes a $Y$ (400 pesos), lo que es posible dado que en ambos casos los costos suman 1,200 pesos, y no rebasan la línea de presupuesto del consumidor.

\section{Figura 3}

\section{Combinación de viajes posibles}

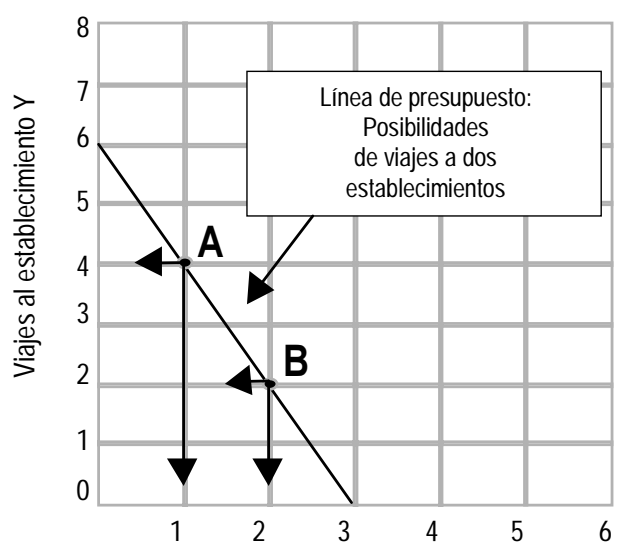

Viajes al establecimiento $X$ 
Ahora bien, la línea de presupuesto puede cambiar si cambia la cantidad de recursos disponibles para transportarse a las unidades comerciales, o si se alteran los costos de transporte. Por ejemplo, si aumentan los recursos disponibles, la línea de presupuesto se desplaza hacia la derecha, indicando que se pueden invertir más recursos en viajar a cada unidad comercial (la línea de presupuesto cambia de $A-B$ a $A^{\prime}-B$ ', en la Figura 4). Si, por el contrario, se reducen los recursos, la línea de presupuesto se desplaza a la izquierda (de $A^{\prime}-B^{\prime}$ a $A-B$, en la Figura 4), lo que implica que ahora se pueden realizar menos viajes a las unidades comerciales.

\section{Figura 4}

\section{Cambios en los recursos disponibles}

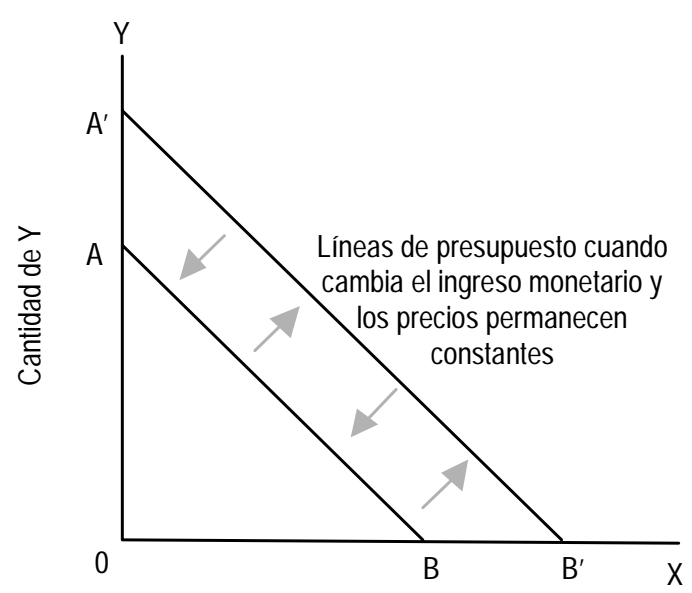

Cantidad de X

\subsubsection{Lo deseable y lo posible}

El supuesto fundamental de que los consumidores tratan de maximizar su utilidad con sus recursos disponibles, significa que deben seleccionar la combinación de bienes más deseable (la que más utilidad les reporte) de entre todas las combinaciones posibles (las que les permita su línea de presupuesto). La Figura 5 ilustra la solución del consumidor. El consumidor no puede cubrir los costos de combinaciones de viajes que se encuentren por encima de su línea de presupuesto. Sería deseable, pero no es posible. Por otro lado, ningún punto situado por abajo de la línea de presupuesto -el llamado espacio de presupuesto- le proporciona 
al consumidor la máxima utilidad derivada de su gasto, ya que puede alcanzar una curva de indiferencia más alta (que implica mayor consumo y por lo tanto mayor utilidad), sin sobrepasar su línea de presupuesto.

\section{Figura 5}

El espacio del presupuesto y el mapa de indiferencia

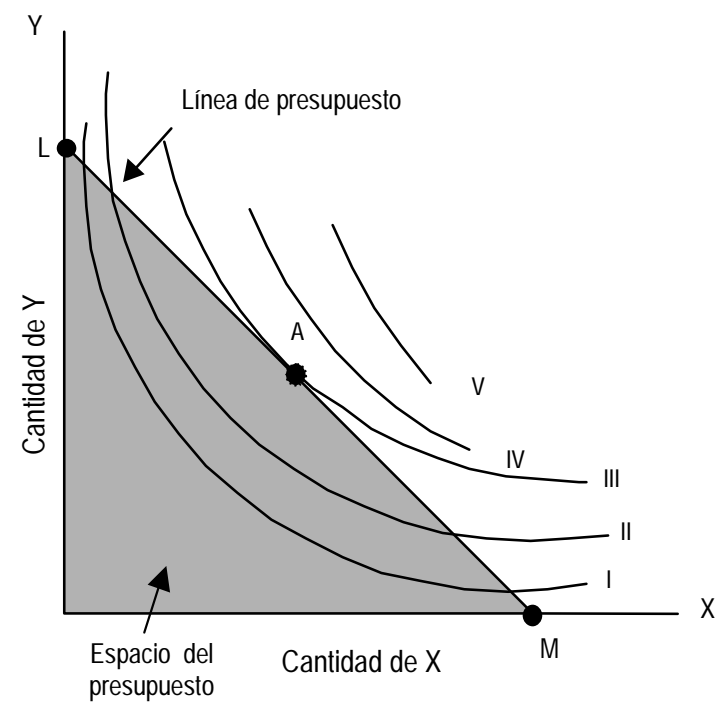

En consecuencia, la posición de máxima utilidad del consumidor -el llamado punto de equilibrio del consumidor- se obtiene donde una curva de indiferencia es tangente a la línea de presupuesto: ese punto concilia lo posible (definido por la línea de presupuesto), con lo deseable (marcado por la curva de indiferencia; es decir, el punto $A$ en la Figura 5). En el caso del consumo de unidades comerciales, el punto de equilibrio representa la combinación de viajes a las unidades que reporta la máxima satisfacción al consumidor, y que puede pagar con sus recursos disponibles.

\subsubsection{Considerando cambios de precios}

En el contexto de las decisiones locacionales, es más común analizar las implicaciones de los cambios en los costos de transporte -para anticipar las consecuencias del cambio de localización de una unidad comercial, o para evaluar diversas opciones de localización para una nueva unidad-que los efectos de los cambios en los recursos disponibles de los consumidores. 
Las consecuencias de los cambios en los costos de transporte en la conducta espacial del consumidor son muy interesantes. Si se reducen o aumentan en la misma proporción los costos de transporte a $X$ y a $Y$, el efecto será el mismo que si aumentaran o se redujeran los recursos del consumidor disponibles para transporte (Figura 4). Pero si, por ejemplo, aumenta sólo el costo de transporte a $X$-sea porque aumenta el costo del medio de transporte o porque $X$ cambia de localización y se ubica a una mayor distancia del consumidor-, la línea de presupuesto incrementará su pendiente (se moverá de $A-B$ a $A-B$ ', en la Figura 6), porque los recursos disponibles alcanzarán para menos visitas a $X$ (el cruce de la línea de presupuesto con el eje horizontal del plano cartesiano estará más cerca del origen; es decir, de cero). Por lo tanto, se genera un nuevo punto de equilibrio para el consumidor (punto $R$, en la Figura 7), porque ahora la línea de presupuesto será tangente a una curva de indiferencia más baja (situada más cerca del origen). A la línea que une puntos de equilibrio sucesivos (la curva que une los puntos $R, Q, P$, en la Figura 7) se le llama curva de precio-consumo.

Figura 6

Cambios en los precios

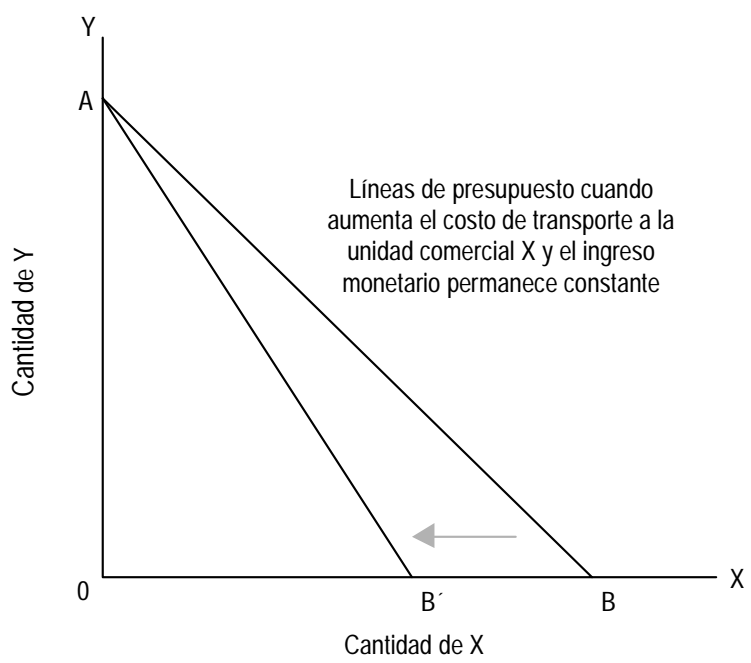


Figura 7

La curva de precio-consumo

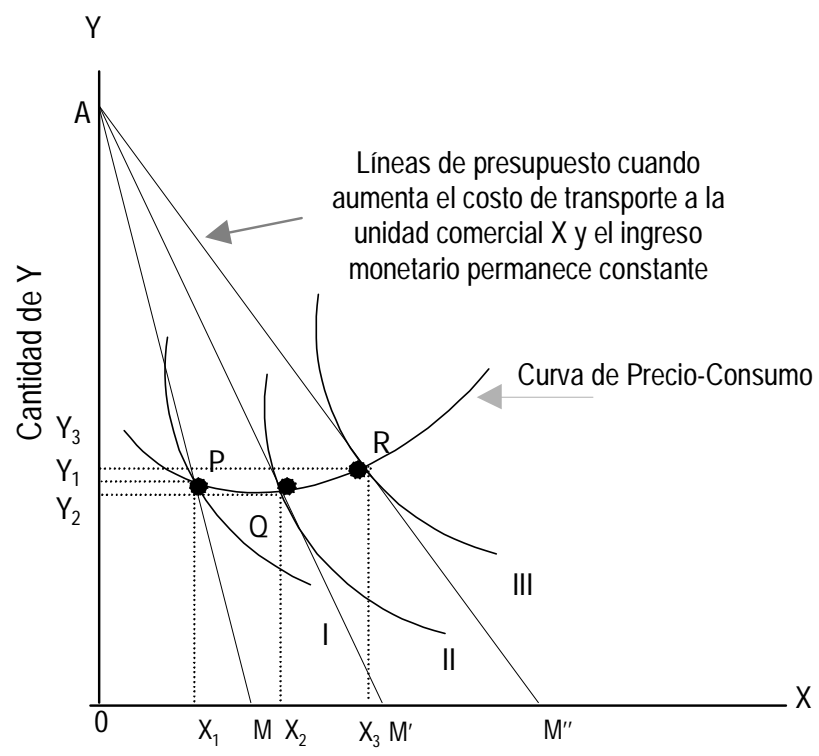

Cantidad de $\mathrm{X}$

En la Figura 7 se observa que en la medida en que aumenta el costo de transporte a la unidad comercial $X$, se reduce la capacidad del consumidor para trasladarse a ese establecimiento. En un primer momento el consumidor puede adquirir OM" viajes a $X-$ siempre y cuando no asista ni una vez a $Y$ - y el punto de equilibrio del consumidor $(R)$ implica que la combinación que más utilidad le reporta es cuando consume $\mathrm{O} x_{3}$ viajes al centro comercial $X$ y $\mathrm{Oy}_{3}$ viajes al centro comercial $Y$. Cuando $X$ cambia de localización a un punto más alejado del consumidor, la cantidad máxima que éste puede adquirir de viajes a $X$ es $O M^{\prime} y$ se alcanza el punto de equilibrio $Q$ (lo que implica que ahora el consumo de viajes a $X$ se reduce a $O x_{2}$ y el consumo de viajes a $Y$ a $O y_{2}$ ); si $X$ vuelve a cambiar de localización a un punto todavía más alejado del consumidor, se alcanza el punto de equilibrio $P$ en donde la cantidad máxima de viajes a $X$ que puede obtener el consumidor baja a OM. Si se grafica el costo de transporte a las unidades comerciales y la cantidad de visitas que el consumidor realiza en cada punto de equilibrio $(R, Q, P)$, el resultado es la curva de demanda (Figura 8). 
Figura 8

La curva de demanda

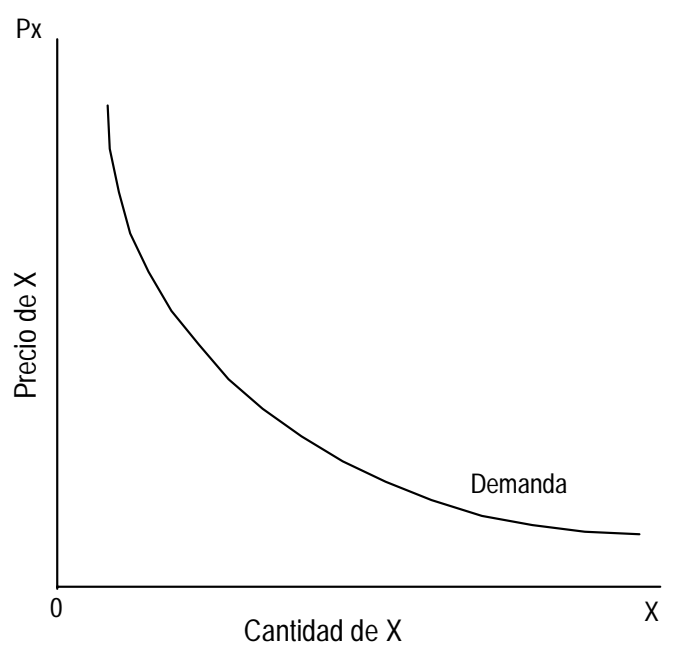

La curva de demanda del consumidor relaciona las cantidades de equilibrio en materia de consumo de bienes o servicios (en nuestro caso, en materia de visitas a unidades comerciales) cuando los recursos disponibles y los precios de los otros bienes y servicios permanecen constantes. De la construcción de la curva de demanda se desprende un principio básico de la microeconomía: cuando el ingreso y los precios de otros bienes permanecen constantes, la cantidad demandada de un bien o servicio varía inversamente con su precio. ${ }^{7}$

Si se traduce este principio microeconómico a términos espaciales, se deriva uno de los argumentos fundamentales de la geografía comercial: si todo permanece constante (en especial la atractividad de los destinos), la magnitud de los flujos entre un origen (por ejemplo, una zona de la ciudad, un barrio o colonia) y un destino (por ejemplo, una unidad comercial) varía inversamente con los costos de transporte. ${ }^{8}$ Este principio microeconómico justifica y respalda la relevancia del análisis locacional de comercios y servicios y genera una de sus premisas básicas: la dimensión

${ }^{7}$ Esto significa que, en términos generales, la cantidad demandada de un bien o servicio disminuirá si aumenta el precio, y aumentará si el precio disminuye.

${ }^{8}$ Cabe recordar que los cambios en los costos de transporte pueden deberse a variaciones en el costo de utilización de los medios de transporte, a cambios en la localización de la unidad comercial, a alteraciones en la localización de los consumidores, o a una combinación de todos estos factores. 
espacial es un referente obligado de la competencia comercial, porque afecta directamente la capacidad de los establecimientos para lograr su objetivo principal: atraer consumidores. Es decir, participar crecientemente del mercado.

\subsubsection{Precio de mercado y precio real: economía y espacio}

Para incorporar lo espacial en el razonamiento microeconómico del consumo de bienes y servicios, resulta fundamental considerar los costos de transporte. Por tanto, es conveniente sustituir el precio de mercado de los bienes (el que se paga en el punto de venta, que es el que considera la microeconomía), por lo que Lloyd y Dicken (1977) llaman el precio real: el precio de mercado, más el costo de transporte que paga el consumidor (por el viaje completo: de ida y vuelta) al punto de venta. ${ }^{9}$

Un ejemplo puede aclarar la importancia del precio real. Supongamos un empresario que vende cierto bien $(Z)$, cuyo precio de mercado es $\$ 2.0$ el kilogramo. Si los consumidores destinan $\$ 8.0$ a la semana para el consumo de $Z$, podrán adquirir $4.0 \mathrm{~kg}$ de $Z$ en ese periodo. Esto es correcto en un análisis microeconómico que excluya la variable espacial (a-espacial). Sin embargo, al introducir la dimensión espacial -y por lo tanto el concepto del precio real de las mercancías- es claro que la cantidad de $Z$ que realmente pueden adquirir los consumidores depende de la suma de los dos componentes del precio real: el precio de mercado y el costo de transportarse al punto de venta. Esto significa que mientras más lejos se localice el consumidor del punto de venta -en nuestro caso: de la unidad comercial- menor será la cantidad de $Z$ que puede adquirir con sus recursos disponibles $(\$ 8.0)$, porque mayor será la parte de ese dinero que tendrá que gastar el consumidor en transportarse al punto de venta. El concepto de precio real establece la conexión entre la microeconomía a-espacial y la geografía comercial.

\footnotetext{
${ }^{9}$ En este sentido, las unidades comerciales ofrecen un servicio cuyo precio de mercado es cero. Es decir, no se paga por acceder a la unidad -aunque el costo de utilizarla esté incluido en el precio de las mercancías-, pero cuyo precio real al consumidor es mayor a cero, porque incluye los costos de transporte (en términos monetarios, temporales, de incomodidades, inconvenientes, energía, etc.) que éste debe pagar para acceder al punto de venta.
} 
Figura 9

Precio de mercado y precio real

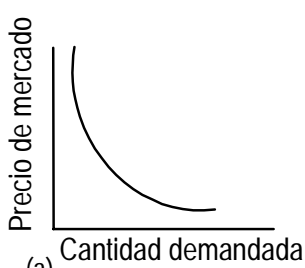

(a)

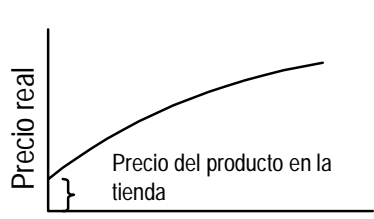

(c)

Distancia

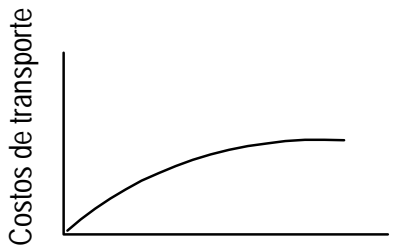

(b) Distancia

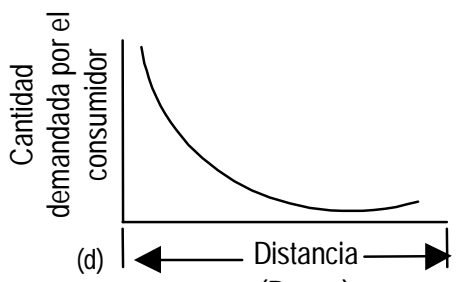

(Rango) (a) La curva de demanda

(c) La curva espacial de los precios (b) Costos y distancia

(d) La curva espacial de la demanda

La Figura 9 ilustra esta conexión. En el inciso " $a$ ” se representa la tradicional curva de demanda de la microeconomía, en donde la cantidad demandada de un bien o servicio varía de manera inversa al precio de mercado (a mayor precio de mercado, menor la cantidad demandada y viceversa). Sin embargo, el precio de mercado no incluye el costo de transporte que paga el consumidor para trasladarse al punto de oferta. Usualmente, el costo de transporte se relaciona de manera directa con la distancia (a mayor distancia recorrida, mayor costo, en el inciso b), y si lo sumamos al precio de mercado obtenemos el precio real de los bienes y servicios. A diferencia del precio de mercado, que no varía espacialmente, el precio real sí registra variaciones espaciales porque incluye los costos de transporte del consumidor (a mayor distancia entre el consumidor y el punto de oferta, mayor será el precio real, en el inciso c). Finalmente, si en el razonamiento microeconómico del comportamiento de la demanda se sustituye el precio de mercado (que es a-espacial) por el concepto de precio real (que incluye los costos de transporte), se deriva la llamada curva del comportamiento espacial de la demanda (inciso $d$ ). La forma de esta curva indica que la cantidad demandada de bienes y servi- 
cios variará inversamente con la distancia (o, mejor dicho, con el costo de transporte) que exista entre el consumidor y el punto de oferta (a mayor costo de transporte, menor cantidad demandada, y viceversa).

La conclusión es clara: la relación entre costo de transporte, distancia, precios y cantidad demandada es crucial en la planeación espacial de unidades comerciales, porque implica que éstas deberán maximizar su accesibilidad al mercado (es decir, a sus clientes) si quieren ser realmente competitivas.

\subsection{Teoría de lugar central: el enfoque de la geografía clásica}

La teoría de lugar central (TLC), elaborada por Walter Christaller en los años treinta, intenta explicar el número, distribución espacial y tamaño de los asentamientos, a partir de la lógica de localización de las actividades terciarias. Es, sin duda, una de las teorías más elegantes de la geografía socioeconómica y ha ofrecido sustento a numerosas políticas de planeación regional (Rondinelli y Shabbir, 1988). Algunos autores han trasladado los argumentos de la TLC a contextos intraurbanos para explicar la organización espacial de las actividades comerciales en las ciudades (Verduzco, 1990), aunque, por sus supuestos y argumentos, la TLC tiene un carácter eminentemente regional.

\subsubsection{Principales argumentos}

Una de las suposiciones más importantes de la TLC es que las ciudades actúan como centros proveedores de bienes y servicios de sus regiones circundantes. La intensidad con la que una ciudad sirve a su región como proveedora de bienes y servicios la llamó Christaller centralidad: una ciudad es más central, en tanto ofrezca más bienes y servicios a su región circundante (Graizbord y Garrocho, 1987).

Dos conceptos resultan básicos para explicar la distribución, número y centralidad de los asentamientos como puntos de oferta comercial y de servicios: umbral y alcance. Por umbral-o, mejor dicho, población de umbral- se entiende la demanda mínima que se requiere para hacer viable la oferta de un bien o servicio. Por ejemplo, la población mínima que se requiere para sostener un cine, una escuela o un centro comercial.

Por alcance de un bien o servicio se entiende la distancia máxima (o costo de transporte máximo) que los consumidores están 
dispuestos a recorrer (pagar) para adquirir un bien o recibir un servicio. A diferencia de la microeconomía, la TLC sí considera los precios reales de los bienes y servicios: la suma de su precio de mercado más el costo de transporte que enfrenta el consumidor para alcanzar el punto de oferta. Entonces, dado un precio de mercado, el precio real variará en el espacio en función directa de los costos de transporte que enfrente el consumidor para llegar al establecimiento de su interés.

Como el precio real de los bienes y servicios se encarece conforme se incrementa el costo de poner en contacto a la oferta y a la demanda, los consumidores elegirán adquirir sus bienes y servicios en los puntos de oferta más próximos. Es decir, en los que minimizan sus costos de transporte. A su vez, los oferentes (los empresarios) decidirán localizarse en los puntos más accesibles a los consumidores, con la finalidad de ser más competitivos en términos de los precios reales de sus productos, atraer más clientes y asegurar mayores ventas. ${ }^{10}$

El concepto de alcance es particularmente relevante porque establece una conexión directa entre la TLC y la teoría microeconómica. Como los bienes y servicios se encarecen al consumidor conforme se incrementan los costos de transporte al punto de oferta, su precio real varía en el espacio: el más bajo se localiza en el punto de oferta mismo, y el más alto en el límite del área de mercado (o alcance del bien o servicio en cuestión). Por lo tanto, si el ingreso disponible de la población es homogéneo, los consumidores próximos al punto de oferta podrán consumir mayor cantidad de bienes y servicios, que los que se encuentren en la periferia del área de mercado, porque enfrentan precios reales más bajos. Exactamente este es el comportamiento de la demanda que prevé la microeconomía, sólo que la TLC lo ubica en un entorno espacial (Figura 9).

Combinando los conceptos de umbral y alcance, y suponiendo una demanda homogénea (en términos de ingreso, valores, gustos y distribución espacial) localizada en una superficie isotrópica (es decir, en una llanura uniforme y plana), es posible establecer dos límites de cobertura espacial para cada bien o servicio: uno -el límite inferior- delimita la demanda mínima necesaria para hacer viable la oferta en términos económicos; el otro -el límite superior- define el área de mercado o la participación máxi-

${ }^{10}$ Nótese que estos argumentos de la TLC se derivan directamente de los planteamientos de la teoría microeconómica sobre la preferencia del consumidor, que se revisó en el apartado 2.1. 
ma del mercado de un bien o servicio (Figura 10). Rebasando este segundo límite, el costo de transporte al punto de oferta que enfrentan los consumidores es tan elevado, que el precio real del bien o servicio no les resulta viable o atractivo.

\section{Figura 10 \\ Relación entre rango y umbral}

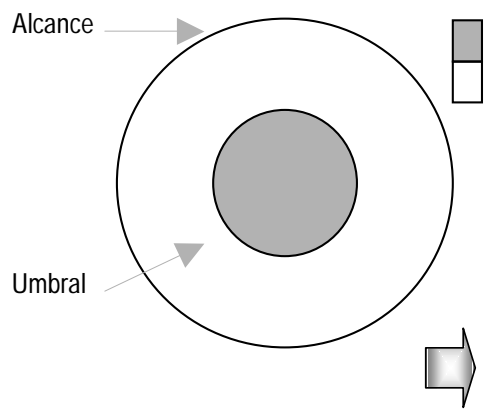

Área que debe cubrirse para mantenerse en el negocio

Área que reporta ganancias extraordinarias

Umbral

El umbral es menor al alcance: el negocio sobrevive y prospera.

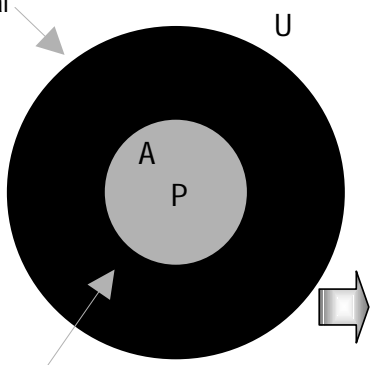

El umbral es mayor al alcance: el negocio quiebra porque la demanda localizada entre $A$ y $U$ no puede pagar el precio de lo que se vende en $P$.

Alcance

Por lo tanto, buscarán acceder a otro punto de oferta que implique menores costos de transporte y, en consecuencia, precios reales más bajos. ${ }^{11}$ Esta circunstancia abre la posibilidad para que nuevos empresarios entren al mercado, siempre y cuando identifiquen localizaciones que les reporten dos ventajas básicas: ganarle mercado (consumidores) a la competencia y alcanzar umbrales suficientes para hacer viables sus propios negocios.

Si en este contexto (una demanda homogénea localizada en una superficie isotrópica) suponemos que compradores y vendedores son económicamente racionales (es decir, que busquen maximizar su utilidad), los primeros acudirán a la unidad comercial

${ }^{11}$ Christaller asumió que el comportamiento de los consumidores era racional en términos económicos. Por lo tanto, los consumidores toman sus decisiones de dónde comprar, en función de maximizar su utilidad (satisfacción). 
más cercana, y los segundos se localizarán lo más cerca posible de los consumidores; así, este comportamiento espacial generará una distribución territorial de puntos de oferta que maximizará -en términos agregados- tanto la accesibilidad de los consumidores (lo que redundará en precios reales más bajos), como los beneficios de los empresarios (Figura 11a). ${ }^{12} \mathrm{El}$ resultado es un patrón espacial de áreas de mercado circulares que cubre todo el territorio y que, al traslaparse, adoptan una forma hexagonal ${ }^{13}$ (Figuras 11 b y 11c); y una jerarquía de puntos de oferta definida por la centralidad de cada uno de ellos. Las diferencias de centralidad de cada punto de oferta son consecuencia de que -en el proceso de conformación espacial del sistema comercial- algunas localizaciones reportan ventajas estratégicas y permiten cubrir una mayor proporción del mercado. ${ }^{14}$

De acuerdo a los supuestos de Christaller, no existe otra distribución espacial que genere mayores ventajas globales (tanto a los consumidores como a los empresarios). En parte por esto, la TLC ha resultado muy atractiva y ampliamente utilizada en la planeación regional para definir y normar la distribución espacial de servicios públicos (Rondinelli y Shabbir, 1988). No obstante, ha sido menos usada para explicar o planear patrones comerciales a nivel intraurbano, dado que el apoyo que puede ofrecer para tomar decisiones locacionales de unidades comerciales específicas en ambientes comerciales competitivos- es limitado.

El poder analítico de la TLC se reduce aún más cuando se le enfrenta a paisajes comerciales tan complejos como los de las ciudades actuales. Sin embargo, al deducir algunas consecuencias espaciales de la teoría microeconómica, Christaller generó los conceptos fundamentales de umbral y alcance, que son, tal vez, la contribución más importante de la TLC a la planeación espacial de comercios y servicios públicos y privados.

\footnotetext{
${ }^{12}$ Ninguna otra distribución espacial de los puntos de oferta le garantiza a los empresarios -entendidos como grupo- mayores ventas y cobertura del mercado. Sin embargo, debido a su localización espacial relativa, las participaciones del mercado de los empresarios individuales -entendidos como unidades comerciales específicas- serán distintas.

${ }^{13}$ Recordar que los consumidores actúan de manera racional (minimizan los costos de transporte). Por lo tanto, los consumidores localizados en las zonas de traslape, al acudir a la unidad comercial que les resulta más cercana, dividen en dos partes iguales las "zonas que se traslapan" de las áreas de mercado circulares, generando automáticamente áreas de mercado hexagonales (Figura 11a).

${ }^{14} \mathrm{~A}$ pesar de que la TLC supone una superficie isotrópica y una demanda homogénea, algunos puntos de oferta logran ventajas de localización iniciales en el proceso de formación del sistema comercial. La explicación del proceso sería demasiado larga para presentarla en este espacio, pero pueden revisarse los detalles en Lloyd y Dicken, 1977; Carter, 1995; Knox, 1994 y, en general, en los textos de geografía urbana.
} 


\section{Figura 11a}

Conformación de áreas de mercado hexagonales, según la lógica de la teoría de lugar central

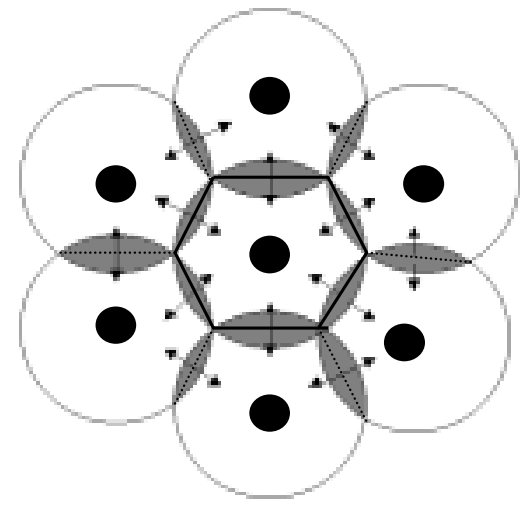

Unidades comerciales

Áreas de mercado circulares

Zonas de traslape entre áreas de mercado

Flujos de compradores de las áreas de traslape a la unidad comercial que resulte más cercana

$\square$ Área de mercado hexagonal que resulta del comportamiento espacial racional de los consumidores

Figura 11b

Patrón final de las áreas de mercado

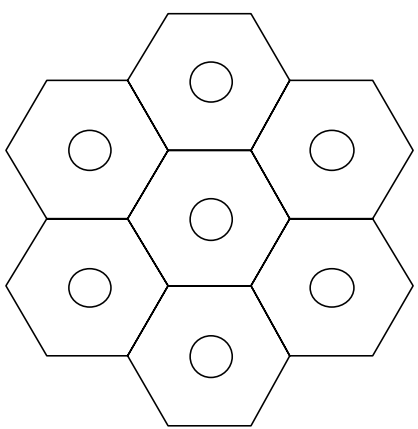


Figura 11c

Áreas de mercado y jerarquía de centros de oferta

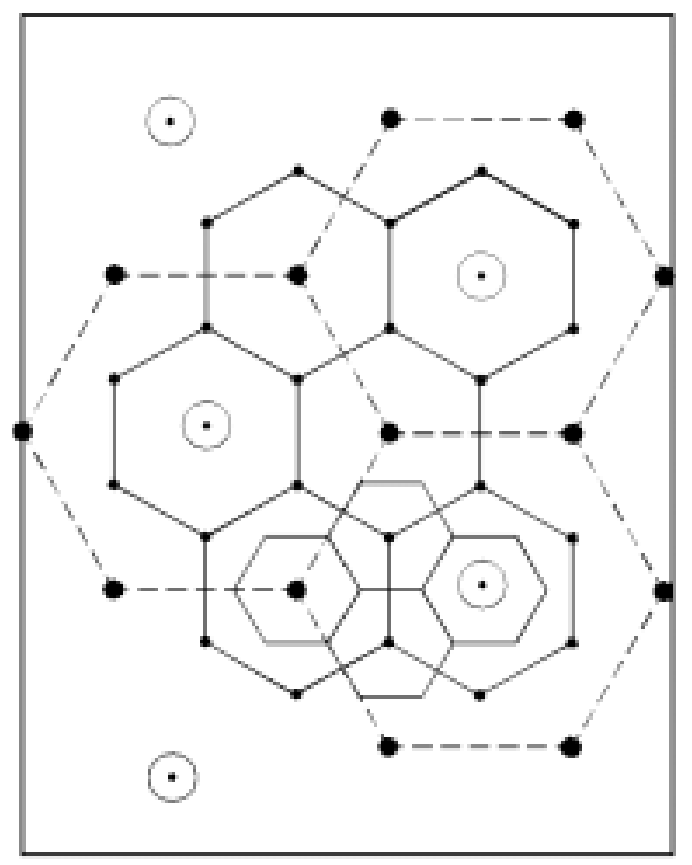

\subsection{Teoría de la subasta del suelo urbano: el enfoque sectorial}

La teoría de la subasta del suelo urbano se fundamenta en el concepto básico de la renta del suelo. Los trabajos pioneros en esta materia se deben a Richard Hurd (1924), quien intentaba explicar la variación del precio de los predios urbanos y su relación con el tipo de uso al que se destinaban.

Apoyándose en los argumentos de Ricardo y Von Thünnen, Hurd partió de que el valor del suelo urbano es producto de la renta o ingreso que genera, y llegó a la conclusión de que en las ciudades, la renta del suelo se basa solamente en la superioridad de la localización. Por lo tanto, el mercado del suelo funciona como una enorme subasta: todos los agentes económicos de la ciudad compiten por obtener el suelo que ofrece mayores ventajas locacionales, y la propiedad de los predios se asigna al mejor postor. Mediante este mecanismo de subasta se define el precio del suelo.

Los agentes económicos que tengan mayor capacidad para extraer beneficios de ciertas localizaciones pagarán el precio más 
alto por unidad de suelo y se lo apropiarán (Carter, 1995). El resultado, por tanto, será un patrón de uso del suelo espacialmente organizado para maximizar la eficiencia económica de las actividades urbanas. En otras palabras, la estructura urbana es producto de la permanente evaluación que hacen los agentes económicos de las ventajas de cada sitio de la ciudad (Ratcliff, 1949).

Esta situación es particularmente clara si se analiza la distribución espacial de las actividades terciarias. Como las unidades comerciales requieren localizarse lo más cerca posible de su mercado (en el centro de las ciudades, junto a importantes vías de comunicación o en áreas prestigiadas y concurridas), los empresarios están dispuestos a pagar el precio más alto por las áreas más accesibles de las ciudades, de las que eventualmente se apropian, tal como lo plantea la teoría.

La teoría de la subasta del suelo urbano retoma las ideas originales de Hurd y las enriquece con otras generadas por diversos economistas y geógrafos urbanos. Haig (1926), por ejemplo, consideró que la accesibilidad determinaba la renta del suelo urbano, e introdujo el concepto de fricción de la distancia. Así, propuso que el precio del suelo comercial se deriva, en gran parte, de los ahorros en costos de transporte que permite cada localización para poner en contacto a la oferta y a la demanda. Dado que el precio real de los bienes y servicios se compone de sus precios de mercado más los costos de transporte -que necesariamente se deben cubrir para que se pongan en contacto oferentes y consumidores- resulta que las áreas más accesibles de la ciudad ofrecen ventajas competitivas a los empresarios comerciales. Por lo tanto, la distribución espacial de las actividades comerciales intraurbanas tiende a ser determinada por el principio de "la reducción de los costos de transporte" (Carter, 1995).

En consecuencia, cada uso del suelo registra una curva de renta/distancia, de tal manera que el precio que cada unidad comercial está dispuesta a pagar por su localización, varía desde un máximo en la parte más accesible a su mercado, hasta un mínimo en las partes en donde la unidad comercial queda aislada de su mercado. Si se supone una ciudad monocéntrica (en donde el centro es el punto de accesibilidad máxima) y se sobreponen todas las curvas de renta/distancia para diferentes tipos de actividades comerciales, se obtiene el perfil de usos de suelo resultante de la subasta del suelo urbano (Figura 12). Si se gira el perfil de usos de suelo y se observa desde un punto situado exactamente arriba del 
eje de las ordenadas (el eje de las $y$ ), se genera un diagrama de círculos concéntricos de usos del suelo, en donde las actividades comerciales predominan en las partes más accesibles de la ciudad, (usualmente el centro, si se trata de una ciudad pequeña monocéntrica; o en varios centros, si se trata de una ciudad mayor de estructura policéntrica).

\section{Figura 12}

\section{La curva de renta/distancia}

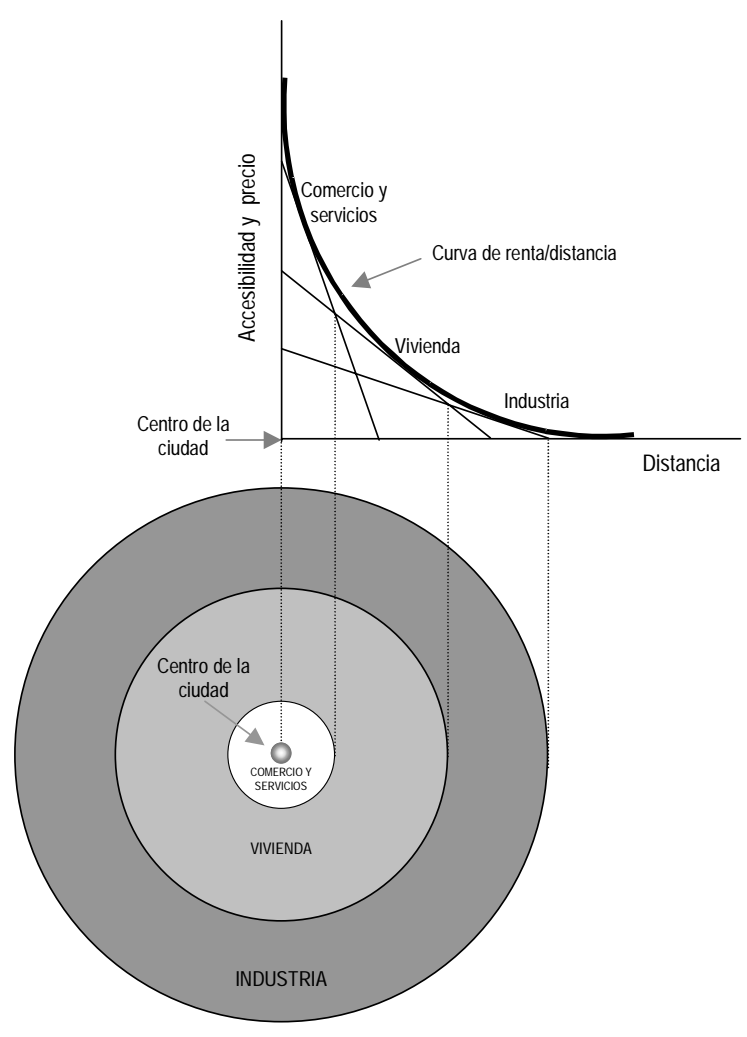

Aunque esta explicación clásica del uso del suelo ha demostrado ser más o menos aceptable, ${ }^{15}$ se han producido numerosas contribuciones conceptuales que la han hecho más compleja, pero también más acorde a lo que ocurre en la realidad (por ejemplo, Gordon et al., 1986; Giuliano y Small, 1991).

${ }^{15}$ Por ejemplo: ciertos comercios especializados -consultorios médicos, joyerías, despachos de abogados u oficinas financieras-requieren localizarse en áreas altamente accesibles al mercado, por lo que están dispuestos a pagar altas rentas por obtener esas localizaciones ventajosas. 
De cualquier manera, dado su carácter agregado, la teoría de la subasta del suelo urbano enfrenta serias limitaciones para apoyar la toma de decisiones locacionales de establecimientos comerciales concretos. Por un lado, si bien los supuestos básicos de la teoría siguen siendo válidos, el modelo clásico de uso del suelo es demasiado simple para explicar la localización de unidades comerciales específicas. Por el otro lado, los modelos más recientes -derivados en su mayoría de argumentos econométricos- son demasiado complejos para ser operativos en la práctica cotidiana de la planeación espacial de unidades comerciales (Gordon et al., 1986).

Si bien la teoría de la subasta del suelo urbano ha demostrado ser poco útil para la planeación espacial de unidades comerciales y de servicios, su revisión es obligada. No sólo por su importante contribución a la economía urbana o por ofrecer algunos argumentos generales que permiten completar la imagen sobre la teoría disponible en geografía comercial, sino porque contiene una conexión básica con las teorías anteriormente descritas: la importancia de los costos de transporte como variable locacional (la llamada fricción de la distancia).

\subsection{Teoría de la interacción espacial: el enfoque de la geografía comercial contemporánea}

\subsubsection{Antecedentes}

La teoría de la interacción espacial (TIE) tiene como antecedente el principio de la gravitación comercial, elaborado por Reilly a principios de los años treinta. En su estudio pionero, Reilly (1931) partía de poner en duda que los consumidores acudieran sistemáticamente a la unidad comercial que les resultaba más cercana (la que minimizaba sus costos de transporte), tal como se derivaba de los razonamientos de la teoría microeconómica y como lo recogería poco más tarde la teoría de lugar central.

Apoyándose en los argumentos de Newton sobre la ley de la gravitación universal, Reilly propuso que la magnitud de los flujos de consumidores entre localidades se relaciona positivamente con la población residente en cada localidad, y negativamente con el cuadrado de las distancias que las separa. Es decir, que las localidades más grandes y accesibles atraen más consumidores que los asentamientos pequeños y más alejados. 
Reilly transformó sus razonamientos en un modelo simple de simulación que permite calcular la intensidad de la interacción entre puntos (o áreas). Lo expresó de la siguiente manera y, por su origen newtoniano, lo llamó modelo gravitacional:

$$
I_{i j}=\left(P_{i} * P_{j}\right) / d_{i j}{ }^{2}
$$

Donde:

$I_{i j}$, es la intensidad de la interacción que se establece entre un punto de origen i y un punto de destino $\mathrm{j}$;

$P_{i}$, es la población del punto de origen i, y

$P_{j}$, es la población del punto de destino j.

$d_{i p}$, es la distancia entre los puntos i y j

El modelo gravitacional fue aplicado y probado en diversas partes del mundo y numerosos estudios han ofrecido evidencia de que la hipótesis de Reilly y su modelo gravitacional son, en lo general, razonablemente aceptables. ${ }^{16}$

Sin embargo, la llamada Ley de Reilly es más intuitiva que conceptual. Se fundamenta arbitrariamente en una analogía mecánica de la física newtoniana, no en una estructura teórica que explique el comportamiento espacial de los consumidores. En consecuencia, registra importantes defectos de manufactura. Por ejemplo, no ofrece argumentos que le otorguen validez teórica a la variable población como atractora de flujos de consumidores; no justifica la relación entre los flujos de consumidores y las variables explicativas (distancia y población); y no fundamenta la propuesta de que los costos de interacción entre dos puntos sean exactamente iguales a la distancia que los separa elevada al cuadrado.

\subsubsection{Principales argumentos de la TIE}

A diferencia del planteamiento de Reilly, la TIE intenta explicar el comportamiento espacial de consumidores y oferentes de bienes y servicios, a partir de razonamientos microeconómicos sobre la relación entre costos de transporte, atractividad de las unidades comerciales y la utilidad (satisfacción) de los consumidores.

\footnotetext{
${ }^{16}$ Cuando los argumentos de Reilly se reducen a la escala intraurbana para explicar los flujos de compradores de diversas zonas de la ciudad a unidades comerciales, se sustituye la variable población -que resulta útil a nivel regional-por otra que exprese la importancia o atractividad de cada unidad comercial (metros cuadrados de la superficie de venta o índice de precios al consumidor, por ejemplo).
} 
La propuesta central de la teoría de interacción espacial es que la magnitud de los flujos de consumidores que atrae una unidad comercial es inversamente proporcional a los costos de transporte que los consumidores deben sufragar para acceder a ella, ${ }^{17} \mathrm{y}$ directamente proporcional a lo atractiva que les resulte ${ }^{18}$ (Wilson, 1980 y 1986). En otras palabras, que la magnitud y dirección de los flujos de consumidores -y las decisiones locacionales de los empresarios- dependen, simultáneamente, de la interacción de dos fuerzas opuestas: los costos de transporte que enfrentan los consumidores (que inhiben la generación de flujos de compradores) y la atractividad de las unidades comerciales (que animan la generación de flujos). Esta explicación es empíricamente comprobable, de carácter general y sumamente sencilla.

Por lo tanto la función de utilidad de los consumidores puede expresarse, de manera general, como sigue:

$$
\mathrm{U}_{\mathrm{ij}}=\left(\mathrm{W}_{\mathrm{j}}\right)^{\mathrm{a}}\left(\mathrm{C}_{\mathrm{ij}}\right)^{-\mathrm{b}}
$$

Donde $U_{i j}$ es la utilidad de la unidad comercial $j$ para el consumidor $i, W_{j}$ es una medida de la atractividad de la unidad comercial $j, C_{i j}$ son los costos de transporte ${ }^{19}$ que separan a la unidad $j$ del consumidor $i$, y $a$ y $b$ son parámetros que reflejan la sensibilidad del consumidor $i$ a los cambios en la atractividad de la unidad $j$ y a los cambios en los costos de transporte, respectivamente.

Dado que la utilidad que puede reportar la unidad comercial decrece conforme se incrementa la distancia al consumidor, el parámetro $b$ tiene signo negativo. Al efecto negativo de los costos de transporte en la utilidad que se deriva de acudir a una unidad comercial se le llama -recordando a Haig (1926)- efecto de la fricción de la distancia, por lo que al parámetro $b$ se le conoce, precisamente, como parámetro de la fricción de la distancia.

${ }^{17}$ Los costos de transporte pueden estimarse en unidades métricas, temporales, monetarias, energéticas o de inconvenientes y molestias.

${ }^{18}$ Una de las grandes preguntas de investigación en la geografía comercial -que se relaciona con la teoría de interacción espacial- es: ¿qué hace atractiva a una unidad comercial? O, de manera más amplia, ¿qué determina la atractividad de las unidades comerciales y cómo se puede medir? Aunque no es difícil imaginar un listado de factores que afectan la atractividad de las unidades comerciales y de servicios, resulta mucho más complicado estimar las inestables relaciones entre ellos y la importancia cambiante de cada uno en contextos comerciales específicos.

${ }^{19}$ Recordar que los costos de transporte pueden estimarse en unidades económicas, de distancia, temporales, de energía física necesaria para realizar el trayecto o en términos de incomodidades e inconveniencias. 
Algo interesante en la estructura básica del modelo es que el efecto negativo de los costos de transporte en la utilidad del consumidor puede ser compensado -con creces- por la atractividad de la unidad comercial. Atractividad que se deriva de la imagen de la firma, calidad, precio y variedad de los bienes y/o servicios ofrecidos, tamaño de la unidad, calidad de la atención, capacidad del espacio de estacionamiento y otros factores que mejoran la experiencia de comprar.

Los consumidores, entonces, evalúan las opciones de compra, contrastando la desutilidad que implican los costos de transporte, con la utilidad que reporta la atractividad de la unidad. Los valores de los parámetros $a$ y $b$ reflejan lo sensibles que son los consumidores a la atractividad y a los costos de transporte en la evaluación de las unidades existentes. ${ }^{20} \mathrm{~A}$ diferencia de la Ley de Reilly, los parámetros de la función de utilidad de los modelos de interacción espacial no se definen arbitrariamente, sino a partir de la conducta espacial observada de los consumidores en áreas de estudio específicas.

En su sencillez conceptual radica gran parte del potencial analítico de la TIE. Al no especificar la naturaleza de los factores que explican la organización espacial de los paisajes comerciales -a saber: costos de transporte y atractividad de los establecimientos- la TIE abre la posibilidad de entenderlos y estimarlos de muy diversas maneras, lo que permite adaptar el razonamiento abstracto de carácter general a situaciones concretas del mundo real.

Por ejemplo, los costos de transporte pueden entenderse como tiempo de transporte, distancia recorrida, energía utilizada en el viaje, inconvenientes del trayecto, costo monetario del viaje, desgaste del medio de transporte; o como una combinación de éstos y otros indicadores que reflejen la importancia de los costos de transporte para los consumidores (Moseley, 1979; Whitelegg, 1982). Por su parte, la atractividad de los establecimientos comerciales se ha relacionado con el tamaño de su área de ventas, imagen comercial, calidad y variedad de los productos, calidad

${ }^{20}$ Por ejemplo, conforme el valor del parámetro $b$ se incrementa, mayor será la sensibilidad del consumidor a los cambios en los costos de transporte. En consecuencia, cuando el valor de $b$ es más significativo que el de $a$, quiere decir que la decisión de los consumidores -respecto de dónde comprar-depende principalmente de la desutilidad o costo de los trayectos a la unidad, ya que son más sensibles al costo de transporte que a la atractividad relativa de las unidades. En este caso, los consumidores tenderán a comprar en la tienda más próxima. La situación opuesta reflejaría que son más sensibles a la atractividad de las unidades que a los costos de transporte. Esta situación es común, por ejemplo, cuando las unidades analizadas son similares y se localizan muy próximas entre sí. 
del servicio, atmósfera de las unidades y muchos otros indicadores más (Wilson, 1986; Auchan, 1999; Wal-Mart, 1999).

Numerosos investigadores han centrado su atención en la definición multivariada de los dos factores explicativos básicos de la TIE, y su definición operativa constituye un complejo problema de investigación que debe resolverse para cada caso de estudio.

Otra ventaja de la TIE es que los indicadores de costos de transporte y atractividad pueden estimarse de manera objetiva, pero también de acuerdo a la percepción subjetiva de los consumidores, lo que añade realismo a los análisis explicativos del comportamiento espacial de la demanda y de las decisiones locacionales de los empresarios comerciales. ${ }^{21}$

\subsubsection{Ventajas operativas}

Finalmente, en términos operativos, la TIE merece una mención especial, ya que ofrece herramientas prácticas que permiten analizar y simular sistemas comerciales complejos. Los modelos de interacción espacial simulan flujos entre orígenes y destinos. En este caso, el flujo de consumidores que sale de la zona de origen $i$ puede representarse como $O_{i}$, mientras que el flujo de consumidores que llega al destino $j$ como $I_{i}$. Estos términos son comúnmente conocidos como orígenes ( $O_{i}$, en donde se origina el flujo) y destinos ( $I_{i}$, a donde llega el flujo), o como productores y atractores (de flujos) respectivamente (Wilson y Bennett, 1985).

Ahora bien, el trayecto del origen $i$ a la unidad $j$ no es gratuito. Implica un costo que puede medirse en unidades temporales, económicas, físicas o por una combinación de éstas y otras variables relacionadas. El costo de viajar de $i$ a $j$ se representa como $C_{i i}$, y se supone -siguiendo los razonamientos de la microeconomía- que el costo de transporte afectará negativamente la intensidad de los flujos que lleguen a los puntos de destino. Por lo tanto, mientras mayor sea el costo de establecer la interacción (por ejemplo, el precio, distancia, tiempo o incomodidades de transporte entre el origen y el destino), menor será la intensidad de los flujos. ${ }^{22}$

\footnotetext{
${ }^{21}$ Incluso, la TIE permite la consideración de teorías psicológicas referentes a las percepciones individuales, por ejemplo: percepciones de precios de las mercancías o de los servicios, de la imagen de las unidades comerciales, de los costos de transporte, de la distancia, y muchas más. Véase por ejemplo Rushton, 1987.

${ }^{22}$ Se supone que el costo de transporte -que puede ser objetivo o subjetivo- está negativamente relacionado con la intensidad de las interrelaciones entre unidades espaciales: a mayor costo, menor la intensidad de las interrelaciones, y viceversa. Sin embargo, algunos atributos del destino pueden generar una fuerza de atracción que contra-
} 
El componente $C_{i j}$ es afectado por un parámetro $b$ que representa lo sensible que son los consumidores de cada zona de origen, ante cambios en los costos de transporte a destinos específicos. Adicionalmente, los modelos de interacción espacial consideran que los puntos de destino pueden tener diferente capacidad para atraer o polarizar flujos de consumidores, de acuerdo a ciertos atributos que los distingan. Esta capacidad atractora se representa en el modelo como $W_{j}$ (la atractividad de cada destino o unidad comercial) por lo que la intensidad de las interrelaciones entre orígenes y destinos se relaciona positivamente con este elemento: mientras mayor es $W_{i}$, mayores son los flujos que polariza una unidad comercial y viceversa. ${ }^{23}$

El objetivo de los modelos de interacción espacial es, por tanto, simular y/o predecir condicionadamente la interacción entre orígenes y destinos $\left(F_{i j}\right)$, en términos del comportamiento de las variables independientes $C_{i j}, O_{i}, y W_{i}$. Estas variables son independientes en el modelo, pero a su vez pueden ser funciones de diversas variables exógenas al modelo.

Por ejemplo, la capacidad de una unidad comercial para atraer compradores $\left(W_{j}\right)$ puede estar relacionada con el nivel de precios de los productos que ofrece, la calidad y variedad de las mercancías, la calidad de la atención, el tamaño del área de ventas y otros. Por lo tanto:

$$
W_{j}=f(a, b, c, \ldots)
$$

Donde $a, b, c .$. son las variables que definen la atractividad de la unidad comercial $j$.

Así, un modelo de interacción espacial ampliamente utilizado para pronosticar flujos de consumidores a unidades comerciales y de servicios y estimar niveles de ventas de unidades existentes o hipotéticas se puede expresar formalmente de la siguiente manera: ${ }^{24}$

$$
\mathrm{F}_{\mathrm{ij}}=\mathrm{A}_{\mathrm{i}} \mathrm{O}_{\mathrm{i}} \mathrm{W}_{\mathrm{j}} \mathrm{C}_{\mathrm{ij}}^{-\mathrm{b}}
$$

rreste la influencia del costo de transporte. Esto complica el modelado de los flujos, pero añade realismo al razonamiento que sustenta a los modelos de interacción espacial.

${ }^{23}$ Aunque los costos de transporte actúan en la dirección opuesta y contrarrestan la atractividad de cada unidad comercial.

${ }^{24}$ Existe una amplia gama de modelos de interacción espacial y el que aquí se presenta, aunque es uno de los más utilizados, es sólo un buen ejemplo. En el Anexo 1 se explica paso a paso, la manera de operar este modelo. 
$F_{i j}=$ Flujo de consumidores de la zona de origen $i$ a la unidad comercial $j$;

$\mathrm{O}_{i}=$ Número de consumidores potenciales en la zona de origen $i$;

$W_{j}=$ Atractividad de cada unidad comercial. Usualmente se estima relacionando el tamaño físico del área de venta de la unidad comercial (como indicador proxy de la cantidad y variedad de productos que ofrece el establecimiento) con un índice de precios al consumidor (Ghosh y McLafferty, 1987). Esta forma de definir el índice de atractividad es consistente con la evidencia disponible de los hábitos de compra de los consumidores mexicanos. En una encuesta reciente, dos de los tres motivos más importantes que reportaron los consumidores mexicanos para elegir el establecimiento donde compran más a menudo fueron: precios bajos (en primer lugar) y mejor surtido (en tercer lugar) (Food Marketing Institute, 1996). El motivo que ocupa el segundo lugar es una mejor ubicación, pero este motivo está implícito en los supuestos del modelo y se materializa en la variable $C_{i{ }^{*}}$

$C_{i j}=$ Costo de viajar de la zona $i$ a la unidad comercial $j$, estimada como la distancia lineal que las separa.

$A_{i}=$ Factor de Balance, que asegura que, $\mathrm{S}_{j} F_{i j}=\mathrm{O}_{i}$ $\mathrm{A}_{\mathrm{i}}=1 / \mathrm{S}_{\mathrm{j}}\left(\mathrm{W}_{\mathrm{i}} \mathrm{C}_{\mathrm{ij}}^{-\mathrm{b}}\right)$

$B=$ Parámetro que se define por calibración o tomando como referencia el comportamiento espacial observado de los consumidores. ${ }^{25}$

A lo largo de los últimos veinticinco años, la TIE se ha enriquecido con diversas aportaciones instrumentales y teóricas. Son notables las de Wilson (1980), que encontró una conexión de la teoría de interacción espacial con la teoría de la maximización de la entropía, generando toda una familia de modelos de interacción espacial; y las aportaciones de Fotheringham (1983a; 1983b; 1985 ; 1986 a y 1986 b) quien en los años ochenta y noventa incorpora elementos nuevos en los modelos de Wilson, con la finalidad de considerar en mayor detalle la estructura espacial de los mercados.

\footnotetext{
${ }^{25}$ Si se tiene información completa de los flujos origen-destino de los consumidores, se puede calcular la sensibilidad de los consumidores ante cambios en los costos de transporte (es decir, la pendiente de la fricción de la distancia), que es precisamente el valor del parámetro $b$. Si sólo se tiene la información del número de consumidores en cada área de origen y el que llega a cada área de destino, se prueban varios valores para $b$, hasta que los resultados del modelo sean lo más parecidos posible a los registrados en la realidad. A esto se le llama calibrar el modelo. Una explicación detallada se puede ver en Garrocho, Chávez y Álvarez, 2003.
} 


\section{Conclusiones. La teoría de interacción espacial como síntesis} de las teorías de localización comercial

Los enfoques teóricos analizados en este texto se complementan entre sí para explicar la localización de unidades comerciales. No obstante, sería deseable sintetizar los diferentes enfoques y contar con uno que los englobara a todos. La propuesta de este artículo es que la estructura conceptual de la TIE permite la articulación coherente de los argumentos de las demás teorías, en un marco operativo útil para la planeación espacial de comercios y servicios. En los siguiente párrafos se trata de probar esta aseveración.

\subsection{Integración de la teoría del consumidor a la TIE}

Comencemos por integrar la teoría del consumidor del enfoque microeconómico a la TIE. La argumentación en este caso es sencilla, porque, por paradójico que parezca, los razonamientos a-espaciales de la teoría microeconómica de la preferencia del consumidor son el sustento mismo de la TIE. Si en la teoría microeconómica se sustituye el precio de mercado por el precio real, y el concepto rígido de recursos económicos disponibles por un concepto más amplio que entienda como recursos no sólo los económicos, sino también otros como los temporales o energéticos (por mencionar sólo algunos), la integración de las dos teorías se observa con toda claridad.

Veamos. El razonamiento microeconómico del comportamiento del consumidor se basa en los siguientes principios: (i) el consumidor trata de maximizar su utilidad, con la restricción de sus recursos limitados; (ii) el consumidor tiene numerosas posibilidades de sustituir y combinar el consumo de bienes y servicios para maximizar su utilidad, pero siempre dentro de los límites de su disponibilidad de recursos, y (iii) si aumenta (o disminuye) el monto de los recursos o el precio de los bienes o servicios, el consumidor reducirá (o aumentará) su consumo. Estos tres principios están claramente contenidos en la TIE.

El primero -el de máxima utilidad-se incluye en la TIE en el balance que debe encontrar el consumidor entre lo que desea y lo que puede consumir. El consumidor pretende maximizar su satisfacción acudiendo a las unidades comerciales que le resulten más atractivas. Pero acudir a ellas implica sufragar un costo de transporte y sus recursos (económicos, temporales, de energía y otros) son limitados. Le es imposible ir a todas las unidades y hacerlo en 
cualquier momento. Por lo tanto, el consumidor tiene que elegir en dónde comprar. Al considerar los costos de transporte no sólo en términos económicos -sino temporales, de inconveniencias, incomodidades o de energía- la TIE implícitamente marca los límites espaciales del consumo: el consumidor no asistirá a unidades que estén localizadas demasiado distantes en términos económicos (costos de transporte), temporales (tiempo de transporte), de inconvenientes (incomodidades del viaje) o energéticos (esfuerzo físico que requiere el viaje). El escenario comercial resultante es mucho más realista que el que genera la microeconomía tradicional.

El segundo principio microeconómico -la combinación del consumo, que se ilustra con las curvas de indiferencia- es el mismo que en la teoría de interacción espacial permite a los consumidores combinar el consumo (la asistencia) de un sinnúmero de unidades comerciales, siempre en busca de maximizar su satisfacción, pero con la restricción permanente del límite de sus recursos. La combinación resultante del consumo de unidades comerciales (es decir, la combinación de viajes a los establecimientos; la llamada conducta espacial del consumidor) representa el punto de equilibrio del consumidor. Como en la microeconomía, en la teoría de interacción espacial este punto de equilibrio es cambiante, y depende de las variaciones en el monto de los recursos disponibles, de los cambios en los costos de transporte y de las alteraciones del poder de atracción de las unidades comerciales. La TIE también da cabida a la idea microeconómica de numerosas combinaciones de consumo, pues posibilita la generación de numerosos patrones de viajes: si cambia el tamaño, número, atractividad y/o localización de una, varias o todas las unidades comerciales existentes; o si cambian la localización, las percepciones, las preferencias y/o los recursos disponibles de los consumidores. Esta flexibilidad de la TIE se deriva de su concepción eminentemente sistémica (en donde todos los elementos y variables se relacionan entre sí), lo que le añade realismo a la representación de la conducta espacial de los consumidores.

Finalmente, el tercer principio básico de la teoría del consumidor -la llamada ley de la oferta y la demanda-también es fundamental en la TIE: dados recursos limitados y atractividades constantes de las unidades comerciales, la magnitud de los flujos de consumidores a las unidades variarán inversamente con los cos- 
tos de transporte (medidos en tiempo, energía, esfuerzo, dinero), como se representa con la curva espacial de la demanda. ${ }^{26}$

\subsection{Integración de la teoría de lugar central a la TIE}

La TIE también contiene los principales argumentos de la teoría de lugar central. Para comenzar, ambas son sistémicas. Sólo que, mientras la teoría de lugar central es parcialmente sistémica -no permite al consumidor combinar su consumo en unidades comerciales del mismo nivel jerárquico, porque éste acude siempre a la unidad más cercana-, la teoría de interacción espacial no impone restricciones de comportamiento a las interacciones (sólo las que se deriven de la insuficiencia de recursos del consumidor). En otras palabras, mientras la teoría de interacción espacial tiene una base conductual-derivada de las percepciones y del comportamiento espacial del consumidor observado en la realidad-que le permite explicar entornos comerciales en términos de probabilidad de ocurrencia, la teoría de lugar central es determinista, ya que asume que frente a unidades comerciales similares, los consumidores siempre viajarán a la más cercana, por lo que es inflexible en la generación de paisajes comerciales.

Como resultado de su concepción cuasimecánica de la conducta espacial de los consumidores -y de lo restrictivo de sus supuestos-, la teoría de lugar central sólo contempla la posibilidad de áreas de mercado discretas (perfectamente delimitadas y de forma hexagonal), sin el mínimo empalme entre ellas. La TIE, por el contrario, se ajusta más a lo que ocurre en el mundo real: supone áreas de mercado continuas y sobreimpuestas. No obstante, los modelos de interacción espacial también podrían generar áreas de mercado discretas y sin empalmes cuando el parámetro de la fricción de la distancia tendiera a infinito (es decir, cuando los consumidores fueran extremadamente sensibles a los costos de

\footnotetext{
${ }^{26}$ En la teoría de interacción espacial, este principio se representa gráficamente con la curva que hemos llamado (en la sección 2.1) del comportamiento espacial de la demanda (que en inglés llaman distance decay effect; Figura 9). Esta gráfica se construye para cada destino, localizando en un espacio cartesiano la afluencia estandarizada de consumidores a la unidad comercial (en el eje de las $y$ ) que se registra a diferentes distancias (la distancia -que puede medirse en unidades temporales, económicas, métricas o incluso en unidades subjetivas- se registra en el eje de las $x$ ). La pendiente negativa de la curva representa la relación inversa entre cantidad demandada y costos de transporte. En los modelos matemáticos de interacción espacial, la pendiente negativa se incluye en el signo negativo del parámetro del costo de transporte, como se vio anteriormente.
} 
transporte), pero ese es sólo un caso especial de configuración de áreas de mercado, y no la regla, como en la teoría de lugar central.

Este punto es muy interesante y vale la pena desarrollarlo en mayor detalle porque muestra, sin lugar a dudas, cómo el paisaje comercial de áreas de mercado hexagonales y discretas derivado de la teoría de lugar central es sólo un caso especial de los paisajes comerciales que se pueden derivar de la TIE.

Para demostrar lo anterior, supongamos un escenario comercial con siete zonas emisoras de flujos de compradores (orígenes) y tres unidades comerciales (destinos) igualmente atractivas para los consumidores, pero localizadas a diferentes distancias de las zonas de origen (véanse los datos del Anexo 1); y todo esto en el marco de los supuestos de la TLC, que se revisaron en la sección 2.2. Con el modelo de interacción espacial que se presentó en la sección 2.4 (y cuyo funcionamiento se explica en detalle en el Anexo 1), simularemos cuatro escenarios comerciales para que no quede duda de cómo al incrementar el parámetro de la fricción de la distancia de un modelo de interacción espacial (y manteniendo todas las demás variables del modelo iguales: ceteris paribus), se conforma el paisaje comercial de áreas hexagonales que predice Christaller con su teoría de lugar central.

En el escenario uno suponemos que los consumidores son indiferentes a la fricción de la distancia (a los costos de transporte), por lo que el parámetro de la fricción de la distancia es igual a cero. En esta situación, a los consumidores localizados en cualquiera de las zonas de origen les da lo mismo en dónde comprar. Es decir, si los costos de transporte ${ }^{27}$ no importan y si las unidades comerciales son igualmente atractivas, ${ }^{28}$ las probabilidades de asistencia de los consumidores a cualquiera de las unidades comerciales serán iguales, y se generará un paisaje comercial de áreas de mercado empalmadas y continuas (Cuadro 1; Figura 13).

\footnotetext{
${ }^{27}$ El tiempo de transporte, los inconvenientes, las incomodidades, los embotellamientos de tráfico, los riesgos del trayecto...

${ }^{28}$ Incluyendo no sólo las características de la unidad comercial, sino las de su entorno: si están en una zona igualmente atractiva, si existen servicios complementarios iguales en la zona (parques, bibliotecas, otras tiendas o puntos de interés...).
} 
Figura 13

Flujos de consumidores en el escenario inicial

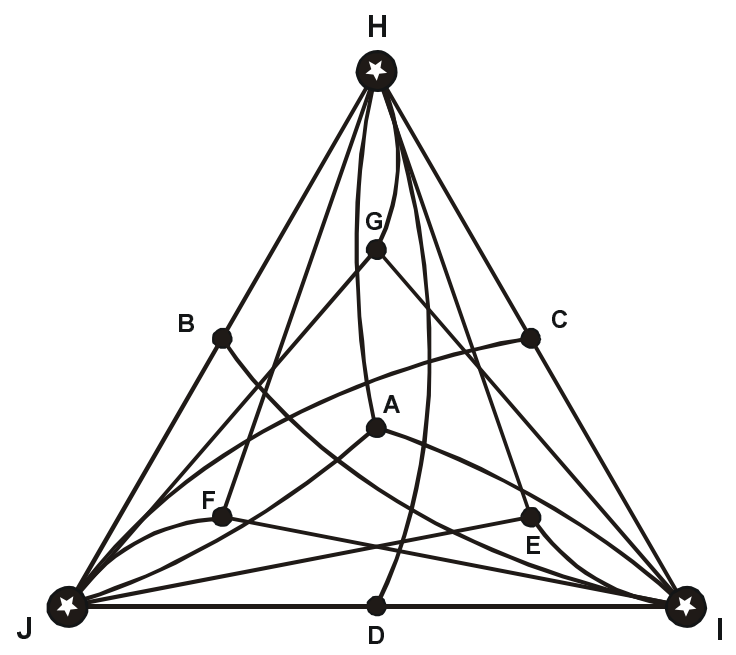

En el escenario dos asignamos un valor de -1.0 al parámetro de la fricción de la distancia. Esto significa que los costos de transporte ya tienen un peso en el comportamiento espacial de los consumidores, lo que se traduce en que prefieren acudir a las unidades comerciales más cercanas. Por ejemplo, la probabilidad de que los consumidores de la zona "B" asistan a las unidades " $\mathrm{H}$ " y "J" es la misma (37.5\%), porque ambas están a la misma distancia de la zona "B", mientras que la probabilidad de que asistan a la unidad "I" es de solo $25.0 \%$, debido a que les resulta más costoso asistir a esta unidad comercial (Cuadro 2). Por su parte, a los consumidores de la zona "A" les es indiferente a cual unidad asistir, puesto que les cuesta lo mismo acudir a cualquiera de ellas. Las zonas que reflejan con mayor intensidad la concentración de flujos a la unidad comercial más cercana son "E", "F" y "G", ya que se encuentran muy alejadas de dos unidades comerciales, pero muy próximas a una de ellas: "E" a la unidad "I" , "F" a la unidad "J", y "G" a la unidad "H"; por lo que les destinan $60.0 \%$ de sus consumidores a estas unidades (Cuadro 2). En este escenario, las áreas de mercado continúan empalmándose y mantienen su continuidad en el territorio (Figura 14). 


\section{Figura 14}

Flujos de consumidores en el escenario intermedio

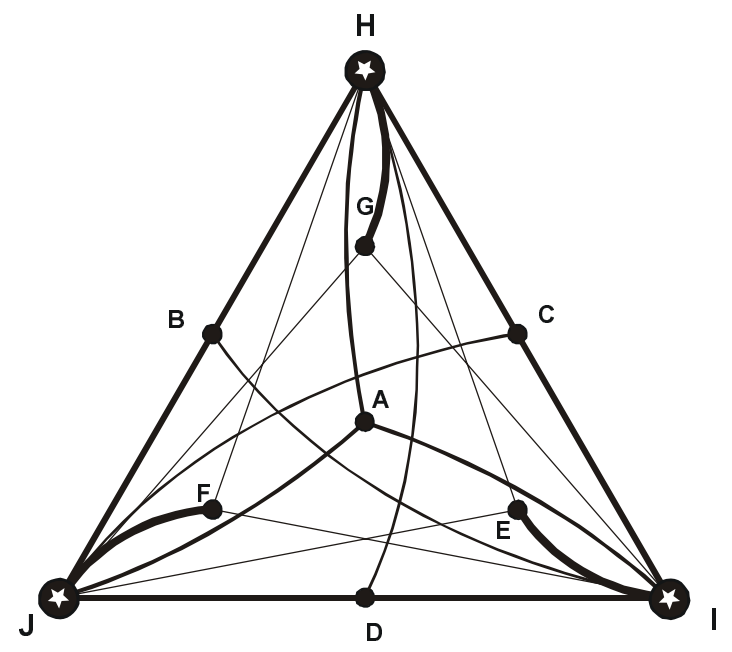

En el escenario tres se incrementa el valor del parámetro de la fricción de la distancia a -5.0, con lo que los consumidores se vuelven mucho más selectivos en cuanto a dónde comprar. ${ }^{29}$ Por ejemplo, sólo $6.2 \%$ de los consumidores de la zona "B" asistirán a la unidad comercial "I", cuando en el escenario dos este porcentaje era de 25.0. Los casos más claros de que las zonas de origen orientan sus flujos a las unidades más cercanas son "E", "F" y "G", que sólo destinan $0.4 \%$ a las dos unidades más alejadas y 99.2\% a la más cercana. Aunque las áreas de mercado siguen empalmándose, los traslapes son menores que en el escenario dos, ya que al concentrar la orientación de sus flujos comienzan a volverse discretas (Cuadro 3).

Finalmente, en el cuarto y último escenario, la fricción de la distancia se incrementa a -50.0 (que en nuestro ejemplo equivale a decir que le asignamos un valor de infinito), con lo que -salvo la zona "A" que está localizada a la misma distancia de las tres unidades comerciales- todas las zonas de origen de compradores dirigirán sus flujos a las unidades más cercanas. Los casos extremos son las zonas "E", "F" y "G", que enviarán el 100.0\% de sus consumidores a las unidades comerciales "I”, “J” y "H”, respectivamente y ni un solo consumidor a las demás unidades (Cuadro

${ }^{29}$ Salvo los de la zona "A", quienes se localizan a la misma distancia de las tres unidades comerciales, por lo que les da los mismo a cuál unidad comercial acudir. 
4). Este escenario extremo, donde todas las zonas de consumidores concentran la orientación de sus flujos a las unidades más cercanas (porque el parámetro de la fricción de la distancia tiende a infinito), genera necesariamente el paisaje comercial de Christaller de áreas hexagonales discretas (Figura 15). Incluso, la zona "A", que se encuentra localizada exactamente a la misma distancia de las tres unidades comerciales divide sus flujos en tres componentes iguales, dirigiendo cada uno a cada unidad comercial. ${ }^{30}$

\section{Figura 15 \\ Flujos de consumidores en el escenario final}

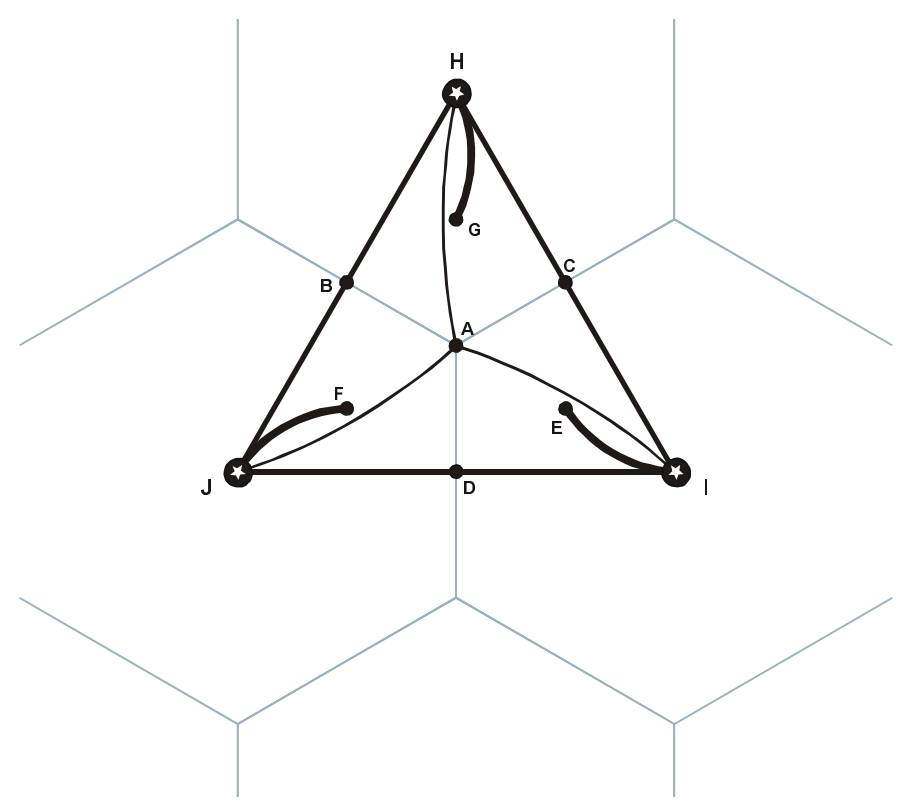

La conclusión de este ejercicio de simulación es evidente: el paisaje comercial de áreas comerciales discretas y hexagonales de la teoría de lugar central es, simplemente, un caso especial de los paisajes que genera la teoría de interacción espacial.

\footnotetext{
${ }^{30}$ En un entorno real -o si flexibilizamos los supuestos tan rígidos de la TLC- podrían ocurrir varias situaciones cuando el parámetro de la fricción de la distancia tiende a infinito. Por ejemplo: el consumidor no acude a los puntos de venta y por lo tanto no adquiere los bienes o servicios que ahí se ofrecen; el consumidor sustituye los bienes y servicios inaccesibles por otros similares, pero accesibles (curanderos por médicos, o "tienditas de la esquina" por hipermercados); o surgen nuevas formas de poner en contacto a la demanda con la oferta (nuevos sistemas de distribución al consumidor o vendedores itinerantes, como ocurre en las zonas rurales).
} 
En cuanto a los dos conceptos básicos de la teoría de lugar central, alcance y umbral, la TIE considera al primero en los costos de transporte, pero no al segundo. Al no considerar el concepto de población de umbral, los estudios locacionales basados en la TIE requieren que el análisis de la capacidad del mercado (o análisis de selección del mercado regional) se realice por separado. Sin embargo, esto no representa un problema importante para el análisis locacional intraurbano, dado que ese tipo de análisis corresponde a otra fase del diseño de la estrategia de localización de firmas comerciales (Ghosh y McLafferty, 1987).

En cambio, el concepto de alcance -la distancia que está dispuesto a recorrer un consumidor para adquirir un bien o servicio- que es fundamental para seleccionar la localización de unidades comerciales, sí está incluido explícita y ventajosamente en la TIE: mientras Christaller sólo podía medir el alcance en términos de distancia-lo que era suficiente para sus propósitos-, la TIE permite estimarlo tanto en unidades de distancia, como económicas, temporales, de energía, esfuerzo físico u otras que convengan al analista, y asignar un límite en el proceso de cálculo, de tal manera que el modelo de interacción espacial que se utilice considere la posibilidad de dejar fuera del mercado ciertas áreas de una ciudad o ciertas localidades de una región. ${ }^{31}$

La TIE incluye también, y con ventajas, la idea de jerarquía de unidades comerciales que se deriva de la argumentación de Christaller. Para explicar las diferencias de importancia de los puntos de oferta (y justificar la jerarquía de comercios y servicios que se observa en la realidad), la teoría de lugar central plantea que en el proceso de conformación del sistema comercial se generan ventajas iniciales de localización. Es decir, que algunos puntos del territorio ofrecen ventajas para la competencia comercial, porque permiten cubrir un mayor mercado. Sólo que una vez que se llega al estado de equilibrio del sistema (cuando se alcanza la distribución espacial de la oferta que maximiza la utilidad agregada de los consumidores y los beneficios totales de los empresarios), las ventajas locacionales de los puntos de oferta ya no cambian, permanecen estáticas. Y no sólo eso, sino que se satura el mercado, no existen nuevos puntos en el territorio que ofrezcan ventajas locacionales

\footnotetext{
${ }^{31}$ En los modelos que se derivan de la teoría de interacción espacial, el alcance se representa por el parámetro de la variable que represente el costo de transporte (que a su vez puede estimarse en diferentes unidades tanto objetivas como subjetivas). Mientras más alto el valor del parámetro, menor será el alcance de una unidad comercial, y viceversa.
} 
y, por lo tanto, no pueden entrar al mercado nuevas unidades comerciales. El sistema comercial alcanza una situación de equilibrio y así permanece.

La TIE, al igual que la teoría de lugar central, también contempla que no todo el territorio ofrece las mismas posibilidades de penetrar el mercado. Sólo que en el enfoque de la TIE, los sitios que ofrecen ventajas locacionales no son estáticos, y su existencia no se restringe a las fases iniciales del proceso de conformación del sistema comercial. La TIE asume que los sitios ventajosos no se agotan, siempre existen, pero su localización no es evidente, sino velada, oculta: hay que descubrirlos. ${ }^{32}$ Como estos sitios cambian constantemente de ubicación -porque el mercado es altamente dinámico e inestable- ${ }^{33}$ las oportunidades para aprovecharlos se abren y se cancelan todo el tiempo. Por lo tanto, si se contempla el paisaje comercial desde un punto de vista sistémico (lo que implica conocer los cambiantes atributos y las dinámicas relaciones espaciales entre oferta y demanda), es posible identificar en el territorio, y para cada momento, los sitios más ventajosos en términos comerciales. De acuerdo a la TIE siempre hay sitios que ofrecen más ventajas competitivas, el reto es encontrarlos. ${ }^{34}$

\subsection{Integración de la teoría de la subasta del suelo urbano a la TIE}

Por último, la TIE también incluye de manera clara el principio básico de la teoría de la subasta de suelo urbano. Es decir, la importancia de los costos de transporte para la localización de actividades comerciales. La primera parte del enunciado fundamental de la teoría de interacción espacial así lo manifiesta: "la proporción de consumidores que atrae una unidad comercial es inversamente proporcional a los $\operatorname{costos}^{35}$ de transporte que en-

\footnotetext{
${ }^{32}$ La expansión es un objetivo básico de las grandes firmas comerciales. Por ejemplo, uno de los propósitos más importantes de los hipermercados Gigante es "abrir más tiendas, acelerar el proceso de renovación de las que ya están operando, mejorar las ventas por metro cuadrado y los márgenes de ganancia para lograr la máxima satisfacción de los accionistas, clientes, proveedores y empleados” (Gigante, 1999).

${ }_{33}$ Porque todo el tiempo están cambiando la magnitud, la localización, el poder de compra, las características demográficas, los gustos y preferencias de los consumidores... el número, los atributos, la distribución espacial y las estrategias competitivas de las unidades comerciales... la red y los sistemas de transporte... la calidad y atractivo de las diferentes zonas de la ciudad... la distribución espacial de todas las actividades urbanas...

${ }^{34}$ Los modelos instrumentados a partir de la teoría de interacción espacial facilitan, precisamente, identificar los sitios que ofrecen ventajas competitivas comerciales desde el punto de vista locacional (Fotheringham y O’Kelly, 1989; Ghosh y McLafferty, 1987).
} 
frentan los consumidores...”. Me parece innecesario abundar más en este punto.

\section{Comentario final}

Antes de finalizar este texto, habría que subrayar que además de que la TIE permite sintetizar coherentemente los argumentos más importantes de las demás teorías de localización comercial-como espero haberlo demostrado en este texto-, hay una razón adicional para preferirla sobre todas ellas, que no es de carácter conceptual, sino operativa: la TIE ha permitido la generación de modelos matemáticos que facilitan realizar análisis locacionales sofisticados en contextos comerciales reales; las demás teorías no. Tienen gran utilidad conceptual, pero en comparación con la TIE, poca utilidad práctica. ${ }^{36}$ Esta característica de la TIE también se demostró en este texto, cuando se utilizó un modelo de interacción espacial para simular la conformación del paisaje comercial de Christaller.

Concluyendo, la TIE incluye a los demás enfoques conceptuales sobre la conducta espacial de los consumidores y los oferentes -por lo que ofrece una plataforma sólida para apoyar los análisis locacionales de firmas comerciales y de servicios- y con sus modelos de simulación ofrece ventajas operativas que la hacen mucho más práctica para diseñar estrategias locacionales de firmas comerciales y de servicios concretas en el mundo real.

${ }^{35}$ De nuevo -vale la pena recalcarlo-, entendiendo los costos de transporte en todas sus dimensiones y en su más amplio sentido y significado.

${ }^{36}$ Hay que recordar que el análisis locacional es eminentemente práctico, pero debe estar sustentado en una plataforma teórica sólida que ofrezca mayor estabilidad que el simple sentido común. 
Anexo 1

Operación de un modelo de interacción espacial

\begin{tabular}{|c|c|c|c|}
\hline \multicolumn{5}{|c|}{ Matriz de distancias: $\left(\mathbf{C}_{\mathbf{i j}}\right)$} \\
\hline A & H & I & J \\
\hline B & 4 & 4 & 4 \\
C & 4 & 6 & 4 \\
D & 4 & 4 & 6 \\
E & 6 & 4 & 4 \\
F & 6 & 2 & 6 \\
G & 6 & 6 & 2 \\
\hline
\end{tabular}

\section{Fricción de la distancia: (-b)}

$$
\begin{array}{ll}
b_{h}= & 0 \\
b_{i}= & 0 \\
b_{j}= & 0
\end{array}
$$

\section{Población consumidora: $\left(\mathrm{O}_{\mathrm{i}}\right)$}

$\begin{array}{cr}\text { A } & 100 \\ \text { B } & 100 \\ \text { C } & 100 \\ \text { D } & 100 \\ \text { E } & 100 \\ \text { F } & 100 \\ \text { G } & 100 \\ \text { suma } & 700\end{array}$

Atractividad de las unidades comerciales y de servicios: $\left(W_{j}\right)$

$\begin{array}{cl}\text { H } & 20 \\ \mathbf{I} & 20 \\ \mathbf{J} & 20\end{array}$




\section{Anexo 1 \\ Pasos para la operación del modelo}

Paso 1:

Paso 2:

\begin{tabular}{|c|c|c|c|}
\hline \multicolumn{5}{|c|}{$\left(\mathbf{C}_{\mathrm{ij}}\right)^{-\mathbf{b}}$} & $\mathbf{I}$ & $\mathbf{J}$ \\
\hline & $\mathbf{H}$ & 1.0 & 1.0 \\
\hline $\mathbf{A}$ & 1.0 & 1.0 & 1.0 \\
$\mathbf{B}$ & 1.0 & 1.0 & 1.0 \\
$\mathbf{C}$ & 1.0 & 1.0 & 1.0 \\
$\mathbf{D}$ & 1.0 & 1.0 & 1.0 \\
$\mathbf{E}$ & 1.0 & 1.0 & 1.0 \\
$\mathbf{F}$ & 1.0 & 1.0 & 1.0 \\
\hline $\mathbf{G}$ & 1.0 & &
\end{tabular}

\begin{tabular}{|c|c|c|c|c|}
\hline \multicolumn{5}{|c|}{$\mathbf{W}_{\mathbf{i}} \mathbf{C}_{i j}{ }^{-b}$} \\
\hline
\end{tabular}

Paso 3:

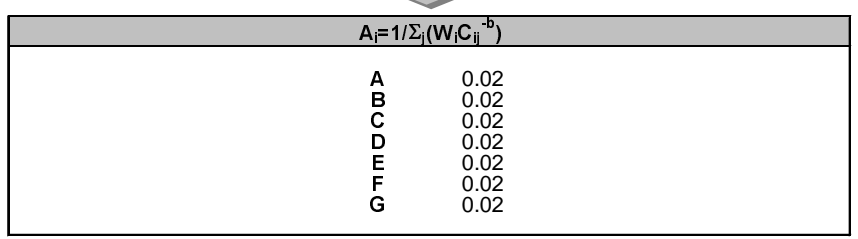

Paso 4:

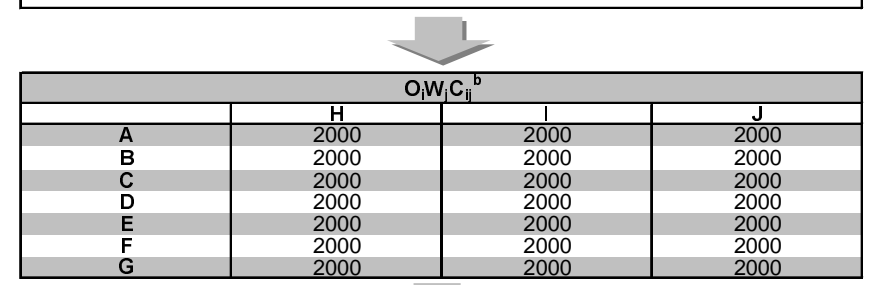

Resultados:

\begin{tabular}{|c|c|c|c|c|}
\hline \multicolumn{5}{|c|}{$\mathbf{A}_{\mathbf{i}} \mathbf{O}_{\mathbf{i}} \mathbf{W}_{\mathbf{j}} \mathbf{C}_{\mathbf{i j}}{ }^{\mathbf{b}}$} \\
\hline $\mathbf{H}$ & $\mathbf{H}$ & $\mathbf{J}$ & suma \\
\hline A & 33.3 & 33.3 & 33.3 & 100 \\
B & 37.5 & 25.0 & 37.5 & 100 \\
C & 37.5 & 37.5 & 25.0 & 100 \\
D & 25.0 & 37.5 & 37.5 & 100 \\
E & 20.0 & 60.0 & 20.0 & 100 \\
F & 20.0 & 20.0 & 60.0 & 100 \\
G & 60.0 & 20.0 & 20.0 & 100 \\
\hline suma & 233 & 233 & 233 & 700 \\
\hline
\end{tabular}




\section{Cuadro 1}

Flujos de consumidores en el escenario inicial con la fricción de la distancia igual a cero $\mathrm{A}_{\mathrm{i}} \mathrm{O}_{\mathrm{i}} \mathrm{W}_{\mathrm{j}} \mathrm{C}_{\mathrm{ij}}^{\mathrm{b}}$

\begin{tabular}{|c|c|c|c|c|}
\hline & H & I & J & suma \\
\hline A & 33.3 & 33.3 & 33.3 & 100 \\
B & 33.3 & 33.3 & 33.3 & 100 \\
C & 33.3 & 33.3 & 33.3 & 100 \\
D & 33.3 & 33.3 & 33.3 & 100 \\
E & 33.3 & 33.3 & 33.3 & 100 \\
F & 33.3 & 33.3 & 33.3 & 100 \\
G & 33.3 & 33.3 & 33.3 & 100 \\
\hline suma & 233 & 233 & 233 & 700 \\
\hline
\end{tabular}

\section{Cuadro 2}

Flujos de consumidores en el escenario dos con la fricción de la distancia igual a -1.0

$$
\mathrm{A}_{\mathrm{i}} \mathrm{O}_{\mathrm{i}} \mathrm{W}_{\mathrm{j}} \mathrm{C}_{\mathrm{ij}}^{\mathrm{b}}
$$

\begin{tabular}{|c|c|c|c|c|}
\hline & H & I & J & suma \\
\hline A & 33.3 & 33.3 & 33.3 & 100 \\
B & 37.5 & 25.0 & 37.5 & 100 \\
C & 37.5 & 37.5 & 25.0 & 100 \\
D & 25.0 & 37.5 & 37.5 & 100 \\
E & 20.0 & 60.0 & 20.0 & 100 \\
F & 20.0 & 20.0 & 60.0 & 100 \\
G & 60.0 & 20.0 & 20.0 & 100 \\
\hline suma & 233 & 233 & 233 & 700 \\
\hline
\end{tabular}

\section{Cuadro 3}

Flujos de consumidores en el escenario tres con la fricción de la distancia igual a -5.0

$$
\mathrm{A}_{\mathrm{i}} \mathrm{O}_{\mathrm{i}} \mathrm{W}_{\mathrm{j}} \mathrm{C}_{\mathrm{ij}}^{\mathrm{b}}
$$

\begin{tabular}{|c|c|c|c|c|}
\hline & H & I & J & suma \\
\hline A & 33.3 & 33.3 & 33.3 & 100 \\
B & 46.9 & 6.2 & 46.9 & 100 \\
C & 46.9 & 46.9 & 6.2 & 100 \\
D & 6.2 & 46.9 & 46.9 & 100 \\
E & 0.4 & 99.2 & 0.4 & 100 \\
F & 0.4 & 0.4 & 99.2 & 100 \\
G & 99.2 & 0.4 & 0.4 & 100 \\
\hline suma & 233 & 233 & 233 & 700 \\
\hline
\end{tabular}


Cuadro 4

Flujos de consumidores en el escenario cuatro con la fricción de la distancia tendiendo a infinito

$\mathrm{A}_{\mathrm{i}} \mathrm{O}_{\mathrm{i}} \mathrm{W}_{\mathrm{j}} \mathrm{C}_{\mathrm{ij}}^{\mathrm{b}}$

\begin{tabular}{|c|c|c|c|c|}
\hline & H & I & J & suma \\
\hline A & 33.3 & 33.3 & 33.3 & 100 \\
B & 50.0 & 0.0 & 50.0 & 100 \\
C & 50.0 & 50.0 & 0.0 & 100 \\
D & 0.0 & 50.0 & 50.0 & 100 \\
E & 0.0 & 100.0 & 0.0 & 100 \\
F & 0.0 & 0.0 & 100.0 & 100 \\
G & 100.0 & 0.0 & 0.0 & 100 \\
\hline suma & 233 & 233 & 233 & 700 \\
\hline
\end{tabular}




\section{Bibliografía}

Alexander, I. (1979), Office location and public policy, Longman, Londres, UK.

Alonso, W. (1964), Location and land use, Harvard University Press, Cambridge, usA.

Applebaum, W. (1966), "Methods for determining sfore trade areas, marketing penetration and potencial sales", Journal of Marketing Research, 3, pp.127-141.

Auchan (1999), Página de Internet.

Berry, B., B. Epstein, A. Ghosh, R. Smith y B. Parr (1988), Market centers and retail location: theory and applications, Prentice Hall, New Jersey, usA.

Carter, H. (1995), The study of urban geography, Books Britain, London, UK.

Christaller, W. (1966), Central places in Southern Germany, Englewood Cliff, New Jersey, usA.

Davies, R.L. y D.S. Rogers (1984), Store location and store assessment research, Wiley and Sons, Chichester, UK. Ferguson, C. E. y J. P. Gould (1983), Teoría microeconómica, Fondo de Cultura Económica, México.

Food Marketing Institute (FMI) (1996) Tendencias en México: actitudes del consumidor y el supermercado, con la colaboración de la Asociación Nacional de Tiendas de Autoservicio y Departamentales, A.c. y la Organización Gallup, Washington, USA, Departamento de Estudios e Investigación, Food Marketing Institute.

Fotheringham, A. S. y M. O'Kelly (1989), Spatial interaction models, Kluwer Academic Publishers, Londres, UK.

Fotheringham, A. S. (1986b), "Further Discussion on DistanceDeterrence Parameters and the Competing Destinations Model”, Environment and planning A, vol. 18, pp. 553-556. 
Fotheringham, A. S. (1986a), "Modelling Hierarchical Destination Choice", Environment and planning A, vol. 18, pp. 401-418.

- (1985), "Spatial Competition and Agglomeration in Urban Modelling", Environment and planning A, vol. 17, pp. 213-230.

_ (1983b), "Some theorical aspects of destinations choice and their relevance to production-constrained gravity models”, Environment and Planning A, vol. 15, pp. 11211132.

- (1983a), "A new set of spatial-interaction models: the theory of competing destinations", Environment and Planning A, vol. 15 , pp.15-36.

Garrocho C., Chávez, T. y Álvarez J.A., (2003), La dimensión espacial de la competencia comercial, El Colegio Mexiquense, México.

Ghosh, A. y S. L. McLafferty (1987), Location strategies for retail and service firms, Lexington Books, New York, USA.

Gigante (1999), Página de Internet.

Giuliano, G. and KA. Small (1991), "Subcenters in the Los Angeles region”, Regional Science and Urban Economics, núm. 21, pp. 163-182.

Gordon, P.H., Richardson H.W., Wong H.L., (1986), “The population and employment in a polycentric city: the case of Los Angeles”, Environment and Planning A, núm. 18, pp. 161-173.

Graizbord, B. y C. Garrocho (1987), Sistemas de Ciudades: fundamentos teóricos y operativos, El Colegio Mexiquense, México.

Haig, R. M. (1926), "Toward an understanding of the metropolis", Quaterly Journal of Economics, 40. 
Hurd, Richard (1924), Principles of city land values, Nueva York, USA.

Jagoe, A. (2002), Mobile Location Services: The definitive guide, Prentice Hall, New Jersey, usA. Jones, K.G. y J. Simmons (1990), The retail environment, Routledge, Londres, UK.

Knox, P. (1994), Urbanization: an introduction to urban geography, Prentice Hall, New Jersey, usA.

Lösch, A.(1954), The economics of location, Yale University Press, (primera edición en alemán en 1940), New Haven, UsA.

Lloyd, P. Y P. Dicken (1977), Location in space: a theoretical approach to economic geography, Harper and Row, Londres, UK.

Moseley, M. (1979), Accessibility: the rural challenge, Methuen, Londres, UK.

Parr, J.B. (1981), “Temporal change in a central place system”, Environment and Planning A, Núm. 13, pp. 97-118.

Ratcliff, R. U.(1949), Urban Land Economic, McGraw-Hill, New York, USA.

Reilly (1931), The Law of the Retail Gravitation, Nueva York, USA.

Rondinelli, D. y G. Shabbir (1988), Urban services in developing countries: public and public roles in urban development, MacMillan, Londres, UK.

Rushton, G. (1987), "Selecting the objective function in locationallocation analysis", en A. Ghosh y G. Rushton (Eds.), Spatial analysis and location-allocation models, Van Nostrand Reinhold, Nueva York, USA.

Verduzco Chávez, B. (1990), "Centralidad urbana y patrones recientes de localización comercial y de servicios en Tijuana", Estudios Demográficos y Urbanos, Vol. 5, Núm. 2, Mayo-Agosto, El Colegio de México. 
Wal-Mart, (1999), Página de Internet.

Whitelegg, J. (1982), Inequalities in health care: problems of access and provision, Straw Barnes, University of Lancaster, Lancaster, UK.

Wilson, AG.(1986), Store and shopping centre location and size: a review of British research and practice, School of Geography, University of Leeds, Leeds, UK.

- (1980), Geografía y planeamiento urbano y regional, OIKOS-TAU, Barcelona, España.

Wilson, A.G. y R.J. Bennett (1985), Mathematical methods in human geography and planning, Wiley, Londres, UK.

Wilson, B.L. (1984), "Modern methods of sales forecasting: regression models", en R.L. Davies y D.S. Rogers (eds.), Store location and store assessment research, John Wiley and Sons, UK.

Wrigley, N. (1988), Store choice, store location and market analysis, Rutledge, Londres, UK.

Enviado: 1 de junio de 2003. Reenviado: 9 de julio de 2003. Aceptado: 14 de julio de 2003. 
